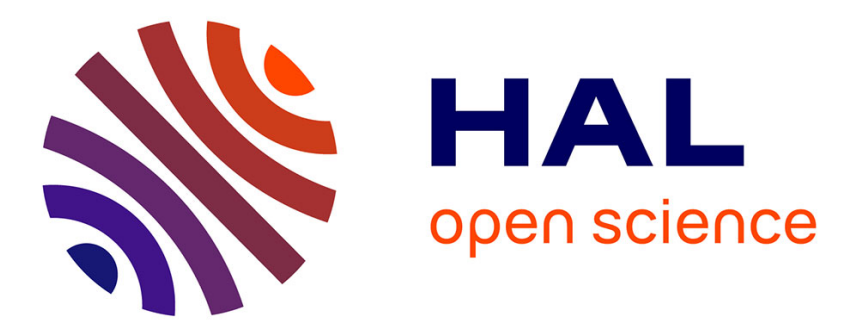

\title{
Strontium Calcium Phosphate Nanotubes as Bioinspired Building Blocks for Bone Regeneration
}

Camila B Tovani, Tamires M Oliveira, Mariana P R Soares, Nadine Nassif, Sandra y Fukada, Pietro Ciancaglini, Alexandre Gloter, Ana P Ramos

\section{- To cite this version:}

Camila B Tovani, Tamires M Oliveira, Mariana P R Soares, Nadine Nassif, Sandra y Fukada, et al. Strontium Calcium Phosphate Nanotubes as Bioinspired Building Blocks for Bone Regeneration. ACS Applied Materials \& Interfaces, 2020, 12 (39), pp.43422 - 43434. 10.1021/acsami.0c12434. hal-03004581

\section{HAL Id: hal-03004581 \\ https://hal.science/hal-03004581}

Submitted on 13 Nov 2020

HAL is a multi-disciplinary open access archive for the deposit and dissemination of scientific research documents, whether they are published or not. The documents may come from teaching and research institutions in France or abroad, or from public or private research centers.
L'archive ouverte pluridisciplinaire HAL, est destinée au dépôt et à la diffusion de documents scientifiques de niveau recherche, publiés ou non, émanant des établissements d'enseignement et de recherche français ou étrangers, des laboratoires publics ou privés. 


\section{Biological and Medical Applications of Materials and Interfaces}

\section{Strontium-calcium phosphate nanotubes as bioinspired building blocks for bone regeneration}

Camila B. Tovani, Tamires Maira Oliveira, Mariana P R Soares, Nadine Nassif, Sandra Yasuyo Fukada, Pietro Ciancaglini, Alexandre Gloter, and Ana Paula Ramos

ACS Appl. Mater. Interfaces, Just Accepted Manuscript • DOI: 10.1021/acsami.0c12434 • Publication Date (Web): 02 Sep 2020

Downloaded from pubs.acs.org on September 3, 2020

\section{Just Accepted}

"Just Accepted" manuscripts have been peer-reviewed and accepted for publication. They are posted online prior to technical editing, formatting for publication and author proofing. The American Chemical Society provides "Just Accepted" as a service to the research community to expedite the dissemination of scientific material as soon as possible after acceptance. "Just Accepted" manuscripts appear in full in PDF format accompanied by an HTML abstract. "Just Accepted" manuscripts have been fully peer reviewed, but should not be considered the official version of record. They are citable by the Digital Object Identifier (DOI®). "Just Accepted" is an optional service offered to authors. Therefore, the "Just Accepted" Web site may not include all articles that will be published in the journal. After a manuscript is technically edited and formatted, it will be removed from the "Just Accepted" Web site and published as an ASAP article. Note that technical editing may introduce minor changes to the manuscript text and/or graphics which could affect content, and all legal disclaimers and ethical guidelines that apply to the journal pertain. ACS cannot be held responsible for errors or consequences arising from the use of information contained in these "Just Accepted" manuscripts. 
1 Strontium-calcium phosphate nanotubes as bioinspired building blocks

*Corresponding author- e-mail: anapr@ffclrp.usp.br

1. Departamento de Química, Faculdade de Filosofia, Ciências e Letras de Ribeirão Preto, Universidade de São Paulo, Ribeirão Preto, SP, Brazil

2. Departamento de Ciências Biomoleculares, Faculdade de Ciências Farmacêuticas de Ribeirão Preto, Universidade de São Paulo, Ribeirão Preto, SP, Brazil

3. Sorbonne Université, CNRS, Collège de France, Laboratoire de Chimie de la Matière Condensée de Paris, 4 Place Jussieu, F-75005 Paris, France

4. Laboratoire de Physique des Solides, Université Paris-Saclay, 91405 Orsay, France

Keywords: biomineralization, calcium phosphate, strontium, collagen, confinement, nanotubes 


\section{Abstract}

2 Calcium phosphates ( $\mathrm{CaPs})$ based ceramics are the most investigated materials for bone

3 repairing and regeneration. However, the clinical performance of commercial ceramics

4 is still far from that of the native tissue which remains as the gold standard. Thus,

5 reproducing the structural architecture and composition of bone matrix should trigger

6 biomimetic response in synthetic materials. Here, we propose an innovative strategy

7 based on the use of track-etched membranes as physical confinement to produce

8 collagen-free strontium substituted-CaPs nanotubes that tend to mimic the building

9 block of bone, i.e. the mineralized collagen fibrils. A combination of high-resolution

10 microscopic and spectroscopic techniques revealed the underlying mechanisms driving

11 the nanotubes formation. Under confinement poorly crystalline apatite platelets

12 assembled into tubes which resembled the mineralized collagen fibrils in terms of

13 diameter and structure of bioapatite. Furthermore, the synergetic effect of $\mathrm{Sr}^{2+}$ and

14 confinement gave rise to the stabilization of amorphous strontium-CaPs nanotubes. The

15 nanotubes were tested in long-term culture of osteoblasts supporting their maturation

16 and mineralization without eliciting any cytotoxicity. The $\mathrm{Sr}^{2+}$ released from the

17 particles reduced the differentiation and activity of osteoclasts in a $\mathrm{Sr}^{2+}$-concentration

18 dependent manner. Their bioactivity was evaluated in a serum-like solution showing

19 that the particles guided spatially the biomimetic remineralization. Further, these effects

20 were achieved at strikingly low concentrations of $\mathrm{Sr}^{2+}$ that is crucial to avoid side

21 effects. Overall, these results open simple and promising pathways to develop a new

22 generation of $\mathrm{CaPs}$ multifunctional ceramics active in tissue regeneration and able to

23 simultaneously induce biomimetic remineralization and control the imbalanced

24 osteoclast activity responsible for bone-density loss. 


\section{INTRODUCTION}

3

4

5 regeneration is an ongoing goal in biomaterials science. This requires reproducing the

6 chemistry and structure of the native tissue. ${ }^{1}$ In bone, the key mechanical and biological

7 features arise mainly from the fibrillar pattern of the extracellular matrix. ${ }^{2}$ Collagen

8 molecules self-assemble into fibrils of 100-200 $\mathrm{nm}$ that are mineralized by apatite

9 platelets providing a typical anisotropic environment that directs cell proliferation and

10 differentiation. ${ }^{3}$ Bone mineral contributes not only for the mechanical properties of the

11 tissue but also supports its remodeling process and biochemical function of ionic

12 reservoir. ${ }^{4}$ This is ascribed to the low degree of crystallinity and the presence of

13 amorphous domains that provides adequate resorption rate. Calcium phosphates (CaPs),

14 are among the most extensively materials used to repair hard tissues injuries thanks to

15 their chemical resemblance to the mineral phase of bone and teeth, suitable

16 biocompatibility and low cost. ${ }^{5}$ However, producing biomimetic CaPs particles remains

17 challenging. In contrast to bone mineral, CaPs based commercial ceramics are usually

18 stoichiometric and highly crystalline rendering poor osteogenic functions as compared

19 to biological graft. ${ }^{6}$ Consequently, rather than regenerative materials, the applications of

$20 \mathrm{CaPs}$ are reduced to biologically passive replacers or fillers. Tuning the

21 physicochemical properties is therefore crucial to trigger biomimetic response in 22 synthetic materials.

To date, several strategies have been proposed to produce bioactive ceramics

24 dedicated to bone regeneration, being the combination of CaPs with collagen regarded 25 as one of the most effective approach to mimic the fibrillar nature of the tissue. ${ }^{7,8}$ 26 However, working with collagen is hard to handle and expensive. Additionally, (i) 
1 denaturation of collagen molecule is easily induced in vitro compromising its ability to

2 self-assemble into fibrils and consequently the biocompatibility of the materials and (ii)

3 reaching fibrils monodisperse in size is not straightforward and requires high

4 concentrated collagen solutions which stabilization is challenging. One dimensional

5 particles with tunable diameter offer an alternative pathway to mimic the mineralized

6 collagen fibrils of bone. Apatite nano/micro tubes have been synthesized through

7 several conditions including hydrothermal routes, high temperatures and addition of

8 stabilizing agents. ${ }^{9}$ Considerable progress has been made, however simultaneously

9 reproducing the structural features of bone mineral and the morphology of collagen

10 fibrils is still challenging and no CaPs particles which resemble the environment of

11 bone extracellular matrix have been achieved without the need of an organic scaffold.

12 Although biomimetic CaPs can repair damages, induce remineralization and

13 osteogenesis, they are not able to regulate the increased osteoclastic activity responsible

14 for osteoporosis. ${ }^{10,11}$ In this sense, in addition to tune the structure and morphology, the

15 incorporation of $\mathrm{Sr}^{2+}$ in bioceramics represents a leap forward in the field of bone

16 regeneration. ${ }^{12}$ Unlike the traditional osteoporosis therapies, $\mathrm{Sr}^{2+}$ exerts a twofold effect

17 on bone cells stimulating osteoblasts activity and decreasing osteoclasts metabolism

18 simultaneously, as desirable for treating and preventing osteoporosis. ${ }^{13}$ Among the

19 materials investigated to locally deliver $\mathrm{Sr}^{2+}$, amorphous CaPs stand out. It is readily

20 degraded by osteoclasts in the acidic environment during bone remodeling yielding both

21 ionic precursors to remineralization and $\mathrm{Sr}^{2+}$ to regulate the imbalanced cellular

22 activity. ${ }^{14,15}$ The use of amorphous CaPs for bone repairing is especially advantageous

23 since they easily induce biomimetic remineralization. ${ }^{10}$ Besides the encouraging clinical

24 results, one should emphasize that the side effects of $\mathrm{Sr}^{2+}$ cannot be neglected; its

25 accumulation in the tissue leads to pathological mineralization such as rickets and 
1 osteomalacia. ${ }^{16-18}$ Therefore, developing biomaterials able to reduce osteoclasts activity

2 at low doses of $\mathrm{Sr}^{2+}$ is of paramount significance since elderly people who may present

3 decreased renal function are the main target of osteoporosis treatments.

4 Here, we propose an innovative strategy based on the use of physical 5 confinement to produce collagen-free $\mathrm{CaP}$ nanotubes which tend to mimic the building 6 block of bone, the mineralized collagen fibrils. Under confinement, poorly crystalline 7 apatite platelets assembled into tubes, which simultaneously resemble both the fibrils 8 present in the extracellular matrix of bone in terms of diameter range and the structure 9 of bioapatite. Although collagen is described to define the structural features of bone 10 mineral, biomimetic apatite was formed here only by using physical confinement, 11 discarding the use of fibrillar polymers. The incorporation of $\mathrm{Sr}^{2+}$ changed the mineral

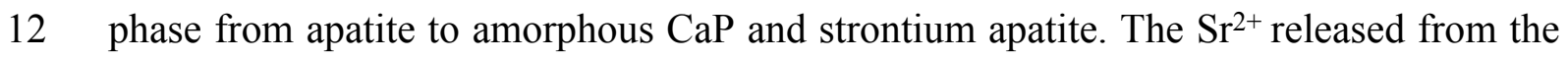
13 particles in the cell culture medium increased alkaline phosphatase activity of 14 osteoblasts and decreased osteoclasts differentiation and resorption in a $\mathrm{Sr}^{2+}$ 15 concentration dependent manner. Notably, these effects were reached at extremely low 16 amounts of $\mathrm{Sr}^{2+}$ as compared to typical therapies based on strontium ranelate and 17 currently reported biomaterials. ${ }^{19-21}$ The ability of the particles to promote biomimetic 18 remineralization was demonstrated by the deposition of bone-like apatite on their 19 surface after immersion in a simulated body fluid (SBF). These results evidence that the 20 particles synthesized herein open perspectives for new ceramics towards bone 21 regeneration. 


\section{2. EXPERIMENTAL PROCEDURE}

\section{$3 \quad$ 2.1 Formation of strontium calcium phosphate $\mathrm{Sr}(\mathrm{CaP})$ nanotubes in physical}

4 confinement

5

6 7

Bioinspired precipitation of CaPs containing different amounts of $\mathrm{Sr}^{2+}(\mathrm{Sr}(\mathrm{CaP}))$ was carried out in confined environment provided by the $200 \mathrm{~nm}$ cylindrical pores of commercial hydrophilic polycarbonate track-etched membranes (Millipore ${ }^{\circledR}$ ) of $20 \mu \mathrm{m}$ thickness, by modifying an approach described elsewhere. ${ }^{22}$ The size of pores was chosen based on the diameter of collagen fibrils in bone. Briefly, $(0.1 \mathrm{wt} . \%$ poly(acrylic acid) (PAA, Sigma MW1800 $\mathrm{g} \mathrm{mol}^{-1}$ ) was dissolved in aqueous solutions containing 0.006 mol L-1 $\mathrm{H}_{3} \mathrm{PO}_{4}$ (Sigma), $\mathrm{CaCl}_{2}$ (Merck P.A.), $\mathrm{SrCl}_{2}$ (Synth P.A.), or a mixture of these salts at different $\mathrm{Sr}^{2+}$ molar percentages $(0,10,50$, and $100 \%)$ in relation to the total number of mols of divalent cations $\left(\mathrm{Ca}^{2+}+\mathrm{Sr}^{2+}\right)$. The total $\left[\mathrm{Ca}^{2+}\right]+\left[\mathrm{Sr}^{2+}\right]$ concentration was $0.01 \mathrm{~mol} \mathrm{~L}^{-1}$. The $(\mathrm{Ca}+\mathrm{Sr}) / \mathrm{P}$ molar ratio was kept constant and equal to 1.67 and initial $\mathrm{pH}=3.5$. The membranes were initially plasma cleaned (Harrickplasma chamber) using $\mathrm{N}_{2}(\mathrm{~g})$ for $2 \mathrm{~min}$. In the sequence, they were immersed into the $\mathrm{PAA} /$ salt solution for $12 \mathrm{~h}$ allowing the penetration of the solution within the pores of the membrane. PAA is described to increase the synthesis yield by promoting the formation of the so-called mineral precursor phase PILP (polymer induced liquid precursor phase) which displays the liquid ability to infiltrate within restricted volumes by capillary action enhancing significantly the intra-membrane versus bulk precipitation. ${ }^{23}$ The membranes were subsequently placed between two glass slides and put into a desiccator containing $\left(\mathrm{NH}_{4}\right)_{2} \mathrm{CO}_{3}$ at room temperature for $12 \mathrm{~h}$, as schematically represented in Figure 1 . The $\left(\mathrm{NH}_{4}\right)_{2} \mathrm{CO}_{3}$ decomposition generates $\mathrm{CO}_{2}(\mathrm{~g})$ and $\mathrm{NH}_{3}(\mathrm{~g})$ that diffuse into the aqueous solutions increasing the $\mathrm{pH}$ which triggers the 
1 mineral precipitation within the pores of the membrane. After precipitation, the surface

2 of the membranes was scraped using filter paper to remove particles that were not

3 formed within the pores. To recover the nanotubes, the membranes were dissolved with

4 chloroform followed by centrifugation $(11000 \mathrm{rpm})$ three times. The particles were then

5 rinsed with ethanol and characterized.

6

\section{$7 \quad 2.2$ Precipitation from the bulk}

8 Precipitation from bulk solution was carried out as control experiments. To this

9 end, $50-\mathrm{mL}$ flasks containing $20 \mathrm{~mL}$ of the PAA/salt starting solutions were placed in a

10 closed desiccator under identical reaction conditions used for the intramembrane

11 precipitation, i.e. precursors concentration, temperature, dissector volume and reaction

12 time. The precipitates were centrifugated, rinsed with ethanol and dried at room

13 temperature.

14 
a

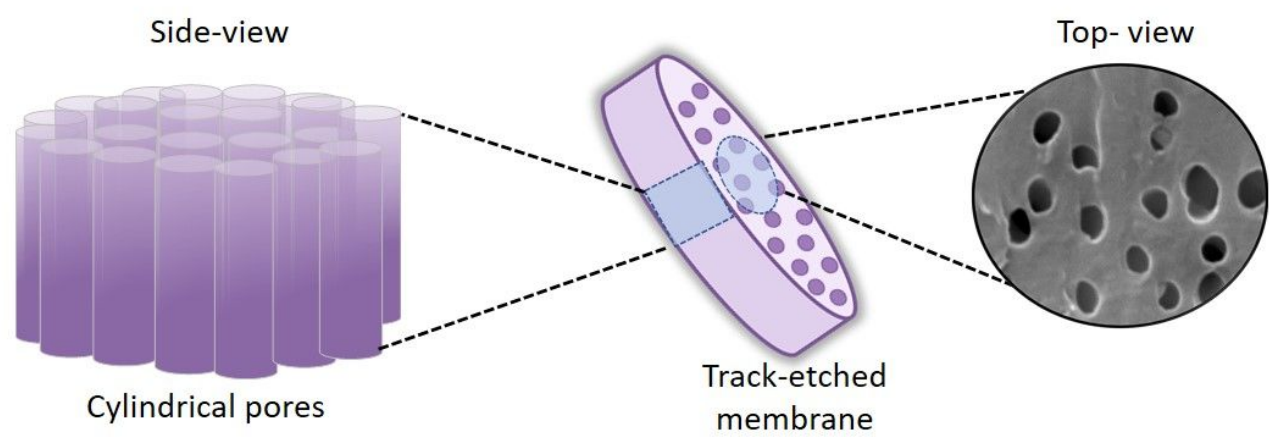

b

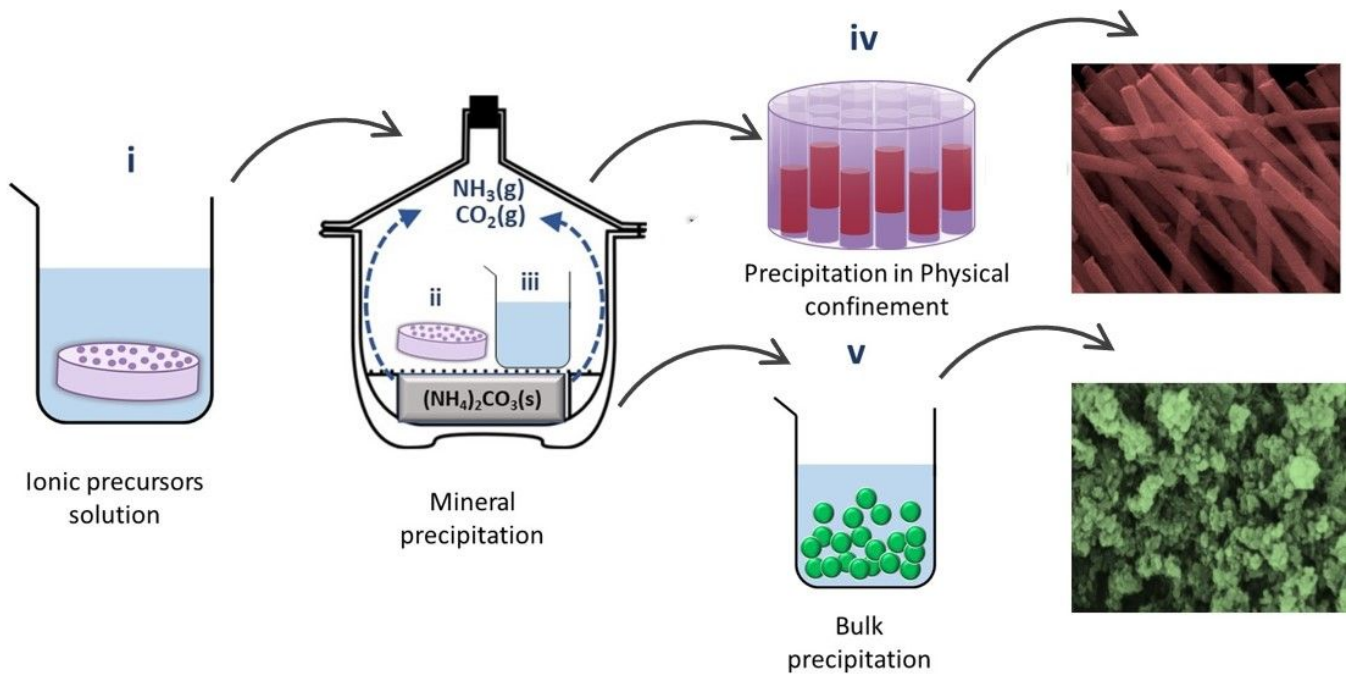

2 Figure 1. (a) Schematic representation of a track-etched membrane used as physical 3 confinement to tune the morphology and size of the nanotubes. The side and top view of the 4 membrane show the cylindrical pores where the precipitation takes place. A SEM image of the 5 surface of a membrane shows the pores. (b) Schematic representation of the precipitation of $6 \mathrm{Sr}(\mathrm{CaP})$ under either physical confinement (i, ii, iv) or in bulk solution (iii and v). The 7 membranes were immersed into the PAA/salt solution for $12 \mathrm{~h}$ (i) and then placed in a 8 desiccator containing $\left(\mathrm{NH}_{4}\right)_{2} \mathrm{CO}_{3}$ (ii) leading to the formation of nanotubes inside the cylindrical 9 pores (iv). The particles (reddish SEM image) were isolated by dissolving the membranes with 10 chloroform followed by centrifugation. A beaker containing the PAA/salt solutions was placed 11 in the desiccator (iii) to conduct the precipitation from bulk solution (v) leading to agglomerated 12 spherical particles (greenish SEM image). 


\section{$2 \quad 2.3$ Ability of the particles to induce biomimetic mineralization in vitro}

The particles were dispersed in simulated body fluid (SBF) at $37^{\circ} \mathrm{C}$ for 5 days to evaluate their ability to induce biomimetic precipitation of apatite in physiological environment. The procedure used to prepare SBF followed the International Standard Organization (ISO 23317) and is described elsewhere. ${ }^{24}$ Briefly, $2.5 \mathrm{mmol} \mathrm{L}-1 \mathrm{Ca}^{2+}, 142$ mmol L-1 $\mathrm{Na}^{+}, 4.2 \mathrm{mmol} \mathrm{L}-1 \mathrm{HCO}_{3}^{-}, 5 \mathrm{mmol} \mathrm{L}{ }^{-1} \mathrm{~K}^{+}, 1.5 \mathrm{mmol} \mathrm{L}-1 \mathrm{Mg}^{2+}, 147.8 \mathrm{mmol} \mathrm{L}^{-1}$ $\mathrm{Cl}^{-}, 1 \mathrm{mmol} \mathrm{L}^{-1} \mathrm{HPO}_{4}{ }^{2-}$ and $0.5 \mathrm{mmol} \mathrm{L}^{-1} \mathrm{SO}_{4}{ }^{2-}$ were dissolved in ultrapure water. The pH was adjusted to 7.4 with $11 \mathrm{~mol} \mathrm{~L}^{-1}$ tris-hydroxymethyl amine methane (Tris) and 1 mol L-1 $\mathrm{HCl}$ aqueous solution. ${ }^{24}$

\subsection{Characterization of the samples}

The morphology of the gold-coated particles was investigated by scanning electron microscopy (SEM) using a Zeiss-EVO 50 microscope under $20 \mathrm{kV}$ accelerating voltage. For transmission electron microscopy (TEM) analysis, the samples were dispersed in ethanol and some drops were deposited on a lacey carbon film on copper grid. Energy dispersive spectroscopy (EDS) mapping of $\mathrm{Ca}, \mathrm{Sr}$ and $\mathrm{P}$ was obtained on a single particle using a HRTEM microscope FEI TECNAI G2 F20 operating at $200 \mathrm{kV}$. TEM images and single particle selected area electron diffraction (SAED) patterns were acquired using a TEM microscope JEOL 2011 operating at $100 \mathrm{kV}$. Energy electron loss spectra (EELS) and scanning transmission electron microscope images (STEM) were acquired in a Nion STEM microscope at $200 \mathrm{keV}$. The chemical groups were identified by Fourier-transform infrared spectroscopy (FTIR) coupled with an attenuated total reflectance (ATR) accessory (Shimadzu-IRPrestige-21), with a resolution of $2 \mathrm{~cm}^{-1}$. The X-ray diffraction patterns were acquired with a Bruker-AXS 
1 D5005 diffractometer using $\mathrm{Cu}-\mathrm{K}_{\alpha}$ radiation at $40 \mathrm{kV}$ and $30 \mathrm{~mA}$. The diffraction peaks

2 were indexed based on the databank of the Joint Committee on Powder Diffraction. The

3 electrophoretic mobility measurements for the determination of zeta-potential $(\zeta)$ were

4 carried out in a Zetasizer Nano ZS (Malvern Instruments). For evaluation of $\zeta$ as a

5 function of the $\mathrm{pH}, 1 \mathrm{mg} \mathrm{mL} \mathrm{m}^{-1}$ of particles was dispersed in $0.001 \mathrm{~mol} \mathrm{~L}^{-1} \mathrm{NaCl}$

6 aqueous solution to keep constant the ionic strength. The $\mathrm{pH}$ was adjusted using $1 \mathrm{~mol}$

$7 \quad \mathrm{~L}^{-1} \mathrm{HCl}$ and $1 \mathrm{~mol} \mathrm{~L}{ }^{-1} \mathrm{NaOH}$. $\zeta$ versus $\mathrm{pH}$ curves were also obtained to investigate the

8 behavior of the particles in the cell culture medium. To this end, the particles were

9 incubated with minimum essential medium ( $\alpha$-MEM, Gibco) supplemented with 10

10 wt. $\%$ fetal bovine serum for $30 \mathrm{~min}$. In the sequence the particles were centrifugated

11 and gently washed with deionized water followed by redispersion in $0.001 \mathrm{~mol} \mathrm{~L}^{-1}$

$12 \mathrm{NaCl}$ aqueous solution.

\subsection{Release of $\mathrm{Sr}^{2+}$}

$\mathrm{The}^{2+} \mathrm{Sr}^{2+}$ released from the particles after immersion in cell culture medium for 1 ,

$163,7,14$ and 21 days was quantified by atomic absorption spectrometry with atomization

17 by acetylene-air flame in the equipment ContrAA 700 (Analytik Jena AG, Jena, 18 Germany). The samples were supplemented with $\mathrm{La}^{3+}$ $19\left(10 \mathrm{~g} \mathrm{~L}^{-1}\right)$ and $\mathrm{K}^{+}\left(1 \mathrm{~g} \mathrm{~L}^{-1}\right)$ and the absorbance read at 460 and $733 \mathrm{~nm}$.

\subsection{Cellular response in vitro}

\subsubsection{MC3T3-E1 viability and mineralization ability}

Osteoblastic lineage cells MC3T3-E1 (American Type Culture Collection-

24 ATCC) were cultured in $\alpha$-MEM (Gibco) supplemented with 10 wt.\% fetal bovine serum and 1 vol.\% penicillin/streptomycin. This is a lineage with an osteoblastic 
1 phenotype that undergoes a proliferation-differentiation sequence, leading to the

2 mineralization of bone-like extracellular matrix. The osteogenic medium was achieved

3 by the addition of ascorbic acid and $\beta$-glycerophosphate. Briefly, the cells were seeded

4 on 24-well plates at the density of $2.10^{4}$ cells per well and incubated in air at $37{ }^{\circ} \mathrm{C}$ and

$5 \quad 5 \% \mathrm{CO}_{2}$. The plated cells were then allowed to attach to the polystyrene well bottoms

6 for 24h, followed by the replacement of the medium for a

$7 \quad 1 \mu \mathrm{g} \mathrm{mL} \mathrm{mL}^{-1}$ suspension of nanotubes $\left(0 \% \mathrm{Sr}^{2+}, 10 \% \mathrm{Sr}^{2+}, 50 \% \mathrm{Sr}^{2+}\right.$ and $\left.100 \% \mathrm{Sr}^{2+}\right)$ in the

8 culture medium. The medium was changed every two days keeping constant the

9 concentration of the particles. Cell viability was determined by MTT (3(4,5-dimethyl-

10 thiazole-2-yl)2,5-diphenyl tetrazolium bromide, Sigma-Aldrich) assay after 7, 14 and 21

11 days of culture using the protocol described by Mosmann. ${ }^{25}$ Cell viability was expressed

12 as the percentage of the average of 3 experiments as compared to the control $(\mathrm{Ct})$

13 without treatment, for each day of culture (100\%). ALP activity was determined by

14 quantifying the hydrolysis of the substrate p-nitrophenyl phosphate (PNPP, Sigma-

15 Aldrich) in the plasma membrane fraction extracted from cells after 7 and 14 days of

16 culture, according to the protocol described elsewhere. ${ }^{26}$ The enzymatic activity was

17 normalized by the total protein content which was estimated by the Hartree

18 methodology, in the presence of $2 \mathrm{wt} . \%$ sodium dodecyl sulfate and using bovine serum

19 albumin as standard. ${ }^{27}$ To this end, the absorbance of the samples was read at $650 \mathrm{~nm}$

20 with a spectrometer. After culturing for 21 days, the formation of the mineralized

21 extracellular matrix was investigated by Alizarin Red S (Sigma-Aldrich) staining

22 according to the methodology described elsewhere. ${ }^{28}$ To avoid the interference of

$23 \mathrm{Sr}(\mathrm{CaP})$ particles, the wells were first gently washed with phosphate saline buffer (three

24 times) removing possible loosely-bounded precipitates from the culture medium. In the

25 sequence, the samples were fixed in 1.5 vol.\% glutaraldehyde at $4{ }^{\circ} \mathrm{C}$ for $12 \mathrm{~h}$ and 
1 dehydrated through a series of ethanol concentrations (30, 50, 70, and 100 vol.\%). The

2 content of the wells was solubilized in acetic acid and neutralized with ammonium

3 hydroxide. The formation of mineral nodules was then followed by reading the

4 absorbance of the samples at $405 \mathrm{~nm}$.

5

$6 \quad$ 2.6.2 Cell morphology

7 SEM was applied to investigate morphology of cells. The cells cultured on the

8 polystyrene discs were fixed in 1.5 vol\% glutaraldehyde at $4{ }^{\circ} \mathrm{C}$ for $12 \mathrm{~h}$, and

9 dehydrated through a series of ethanol concentrations (20, 50, 70, 80, 90 and 100

10 vol.\%), dried using supercritical $\mathrm{CO}_{2}$ conditions and contrasted with $\mathrm{OsO}_{4}$. After coated

11 with gold, the samples were observed on a Zeiss-EVO 50 SEM microscope under $20 \mathrm{kV}$

12 accelerating voltage. The morphology of attached cells was also investigated by

13 confocal microscopy. For this, after the fixation step, the samples were stained with 5

$14 \mu \mathrm{g} \mathrm{mL} \mathrm{m}^{-1}$ acridine orange (Sigma-Aldrich) and then visualized using a confocal laser

15 scanning microscope (Leica TCS SP5). This fluorophore binds to the osteoblast nucleic

16 acids providing a contrasted image. To visualize DNA, the sample was excited with the

$17488 \mathrm{~nm}$ line of an argon laser, and emission was collected between 499 and $541 \mathrm{~nm}$

18 (green). RNA was visualized by exciting the sample with the $458 \mathrm{~nm}$ line of an argon

19 laser, and emission was collected between 642 and $682 \mathrm{~nm}$ (red).

\subsubsection{Osteoclasts differentiation and resorption activity}

21 Bone marrow macrophages (BMMs) were isolated from long bone of 6- to 8-

22 wk-old C57BL/6 mice and were cultured in $\alpha$-MEM (GIBCO, Invitrogen) supplemented

23 with 10 wt.\% fetal bovine serum (FBS; Sigma-Aldrich), 1 vol.\% penicillin-

24 streptomycin, and $30 \mathrm{ng} \mathrm{mL} \mathrm{mL}^{-1} \mathrm{M}-\mathrm{CSF}$ (R\&D Systems). After 3 days, adherents BMMs

25 were collected, seeded at a density of $2.10^{4}$ cells/well in 96-well plates or 
1 hydroxyapatite-coated plates. Cells were cultured for 2 days in osteoclastogenic 2 medium condition: M-CSF (30 $\left.\mathrm{ng} \mathrm{mL} \mathrm{mL}^{-1}\right)$ and RANKL $\left(10 \mathrm{ng} \mathrm{mL} \mathrm{m}^{-1}\right)$. Then, the 3 osteoclastogenic medium was replaced by $1 \mu \mathrm{g} \mathrm{mL}^{-1}$ dispersion of the of $\mathrm{Sr}(\mathrm{CaP})$

4 nanotubes containing $0,10,50,100 \mathrm{~mol}^{\%} \mathrm{Sr}^{2+}$ in the culture medium. Osteoclast5 differentiated cells on day 4 were confirmed by tartrate-resistant acid phosphatase 6 (TRAP) staining (Sigma-Aldrich 387A kit). The osteoclast number (TRAP-positive 7 cells containing 3 or more nuclei) was analyzed in 5 wells per group using ImageJ 8 software (National Institutes of Health). Resorption area was measured in 9 hydroxyapatite-coated 96 well plate (OsteoAssay-Corning) on day 5 of culture. The 10 results were representative of two independent experiments. 


\section{3. RESULTS AND DISCUSSION}

\section{$3 \quad 3.1$ Synthesis of $\mathrm{Sr}(\mathrm{CaP})$ nanotubes: effect of physical confinement and $\mathrm{Sr}^{2+}$} 4 concentration

5

6

The effects of the physical confinement in the precipitation of $\mathrm{Sr}(\mathrm{CaP})$ particles were distinguished by comparison with control experiments in which the precipitation was carried out in bulk solution. SEM images of the polycarbonate track-etched membranes used as physical confinement are shown in Figure S1. The effect of $\mathrm{Sr}^{2+}$ concentration was also investigated. Polydisperse and agglomerated spherical particles formed in the control experiments (Figure 2a). The spherical morphology is typical of apatite grown in the presence of high concentration of $\mathrm{CO}_{3}{ }^{2-} \cdot{ }^{29}$ Well defined tubes formed within the pores of polycarbonate membranes regardless the amount of $\mathrm{Sr}^{2+}$, confirming the role of physical confinement in defining the particles diameter and morphology (Figure 2b). Notably, these particles resemble the collagen fibrils found in the extracellular matrix of bone in terms of diameter range and mineral interface. ${ }^{30}$ To demonstrate the versatility of this approach to control the morphology and size of the particles, $\mathrm{Sr}(\mathrm{CaP})$ tubes with $400 \mathrm{~nm}$ diameter were synthesized using polycarbonate

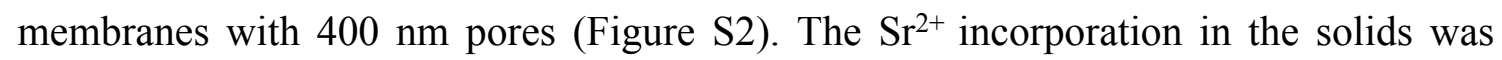
proportional to its concentration in the starting solutions regardless the use of confinement, as determined by TEM-EDS (Table S1).

The mineral composition of the spherical particles precipitated in bulk solution and tubes precipitated under confinement was investigated by XRD (Figures $2 \mathrm{c}$ and $2 \mathrm{~d}$, respectively). In the absence of $\mathrm{Sr}^{2+}\left(0 \% \mathrm{Sr}^{2+}\right)$ apatite was formed in the control together with other CaPs (indicated by * in the diffractogram). Although some peaks could be identified as octacalcium phosphate (OCP) the low amount of material precluded the 
1 complete identification of these additional phases by XRD. Poorly crystalline apatite

2 resembling bone mineral was selectively formed within the membrane pores at $0 \%$

$3 \mathrm{Sr}^{2+} \cdot{ }^{31}$ The addition of $10 \% \mathrm{Sr}^{2+}$ in the control lead to strain in the crystalline structure

4 of apatite as suggested by the broader diffraction peaks (Figure 2c). Moreover, the shift

5 of the 002 peak towards lower values of $2 \theta$ supports the $\mathrm{Ca}^{2+}$ replacement by $\mathrm{Sr}^{2+}$ in the

6 apatite lattice. At the same $10 \% \mathrm{Sr}^{2+}$, amorphous strontium calcium phosphate $\operatorname{Sr}(\mathrm{ACP})$

7 was formed under confinement (Figure 2d). At 50\% $\mathrm{Sr}^{2+}, \mathrm{Sr}(\mathrm{ACP})$ was precipitated in

8 the control as indicated by the characteristic humps at $2 \theta$ close to $30^{\circ}$ (Figure 2c), in

9 agreement with previous investigations. ${ }^{32}$ Additionally, some peaks assigned to

10 strontianite $\left(\mathrm{SrCO}_{3}\right.$, indicated by $\mathrm{S}$ in the diffractogram) were also detected. ${ }^{33}$ This was

11 expected as the critical $\mathrm{pH}$ for the mineral precipitation was triggered by the

12 decomposition of $\left(\mathrm{NH}_{4}\right)_{2} \mathrm{CO}_{3}$. In contrast, diffraction peaks were not observed for the

13 samples containing $50 \% \mathrm{Sr}^{2+}$ precipitated within the membrane's pores, showing that

14 confinement promotes the amorphization of both phosphate and carbonate. This

15 indicates therefore that this sample is formed by a mixture of $\operatorname{Sr}(\mathrm{ACP})$ and amorphous

16 strontium calcium carbonate $\operatorname{Sr}(\mathrm{ACC})$. Increased amount of $\mathrm{Sr}^{2+}$ up to $100 \%$ resulted in

17 the precipitation of strontium hydrogen phosphate for the control, while strontium

18 apatite was formed under confinement. Table S2 summarizes the products obtained in

19 bulk solution and in confinement. $\zeta$ results evidenced the structural changes described

20 by XRD due to the incorporation of $\mathrm{Sr}^{2+}$ in the particles (Figure S3). ATR-FTIR spectra

21 confirmed that, likewise the mineral found in the bone tissue and tooth enamel, the

22 nanotubes are made of carbonated apatite, thus strengthening their biomimetic nature

23 (Figure S4). ${ }^{34}$ This is an important feature considering the application of these particles

24 as building blocks for bone regeneration. 


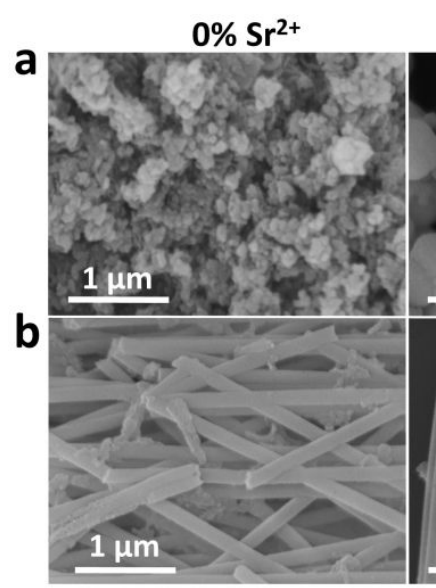

C

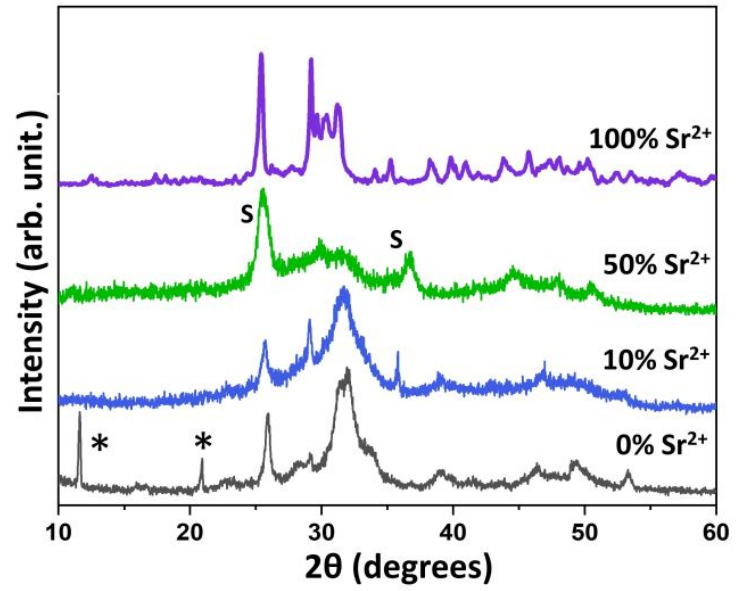

$10 \% \mathrm{Sr}^{2+}$

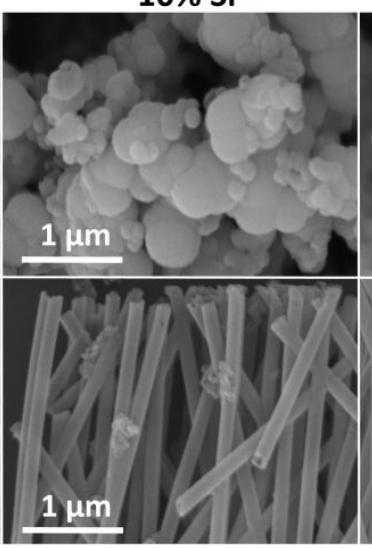

d

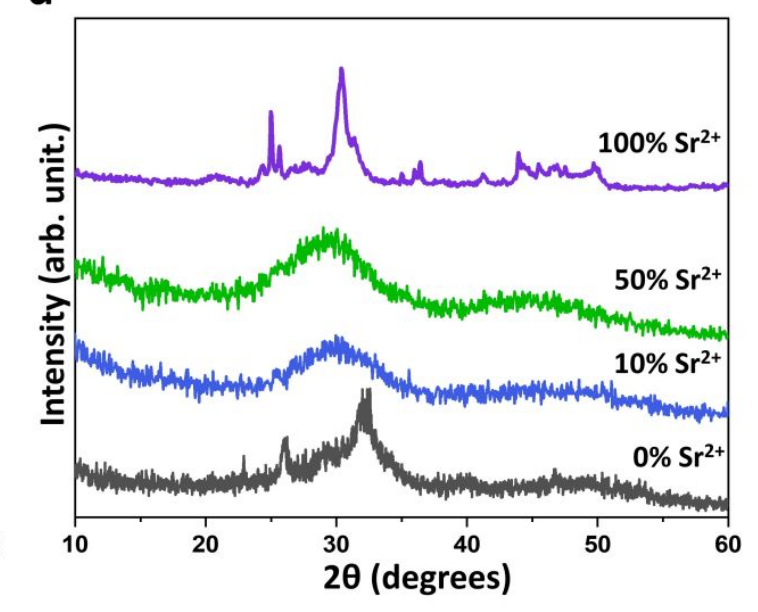

$50 \% \mathrm{Sr}^{2+}$

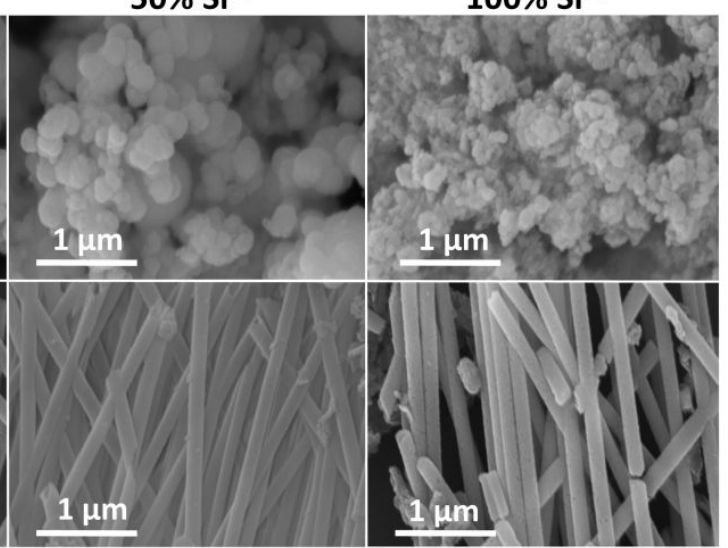

3 Figure 2. SEM images of the phosphate particles formed in bulk solution (a) and in confinement (d). The products formed in bulk solution were indexed as follows: hydroxyapatite

6 for $0 \% \mathrm{Sr}^{2+}$ and $10 \% \mathrm{Sr}^{2+}$ (JCPDS 9-432). The additional peaks (*) observed in the $0 \% \mathrm{Sr}^{2+}$ 7 sample may be due to OCP (JPDCS 26-1056). Strontianite (S) (JPDCS 01-071-4899) was

8 found in the $50 \% \mathrm{Sr}^{2+}$ sample in addition to an amorphous phase $\operatorname{Sr}(\mathrm{ACP})$. Strontium hydrogen

9 phosphate was identified in the $100 \% \mathrm{Sr}^{2+}$ sample (JCPDS 23-105026). The samples formed in

10 confinement were identified as hydroxyapatite $\left(0 \% \mathrm{Sr}^{2+}\right), \mathrm{Sr}(\mathrm{ACP})\left(10 \% \mathrm{Sr}^{2+}\right.$ and $\left.50 \% \mathrm{Sr}^{2+}\right)$ and 11 strontium hydroxyapatite ( $\left.100 \% \mathrm{Sr}^{2+}\right)$ (JPDCS 33-1348). 
The tubes formed under physical confinement were further characterized by

3 TEM-BF (bright field), STEM-HAADF (high angle annular dark field) microscopy and

4 SAED (Figure 3). As expected, the tubes display a diameter of $200 \mathrm{~nm}$. The samples

5 containing 0,10 and $50 \% \mathrm{Sr}^{2+}$ displayed a hollow structure which characterized them as

6 tubes. This was unambiguous from the STEM-HAADF images that were sensitive to

7 the amount of projected materials with higher thickness appearing brighter.

8 Furthermore, vase-like structures were observed suggesting that the precipitation started

9 at the bottom of the membrane and progressed along the pore leading to narrowing tube

10 walls (Figure S5). In the absence of $\mathrm{Sr}^{2+}$, the tubes were polycrystalline composed of

11 nanometric platelets resembling the morphology of apatite in bone. Their apatite

12 structure was confirmed by the typical SAED patterns.

13 The absence of crystalline reflections in the SAED patterns of the $10 \% \mathrm{Sr}^{2+}$ and

$1450 \% \mathrm{Sr}^{2+}$ tubes confirms their amorphous character depicted by XRD. The $100 \% \mathrm{Sr}^{2+}$

15 rods were polycrystalline, with grain sizes of several tens of $\mathrm{nm}$ and unlike the $\mathrm{Ca}^{2+}$ -

16 bearing particles they were not hollow. Elementary EDS-TEM mapping results show

17 that the elements $\mathrm{Ca}, \mathrm{Sr}, \mathrm{P}$, and $\mathrm{O}$ were homogeneously distributed within the $\mathrm{Sr}(\mathrm{ACP})$

18 particles, at least with the resolution of the EDS system (Figure S6). 

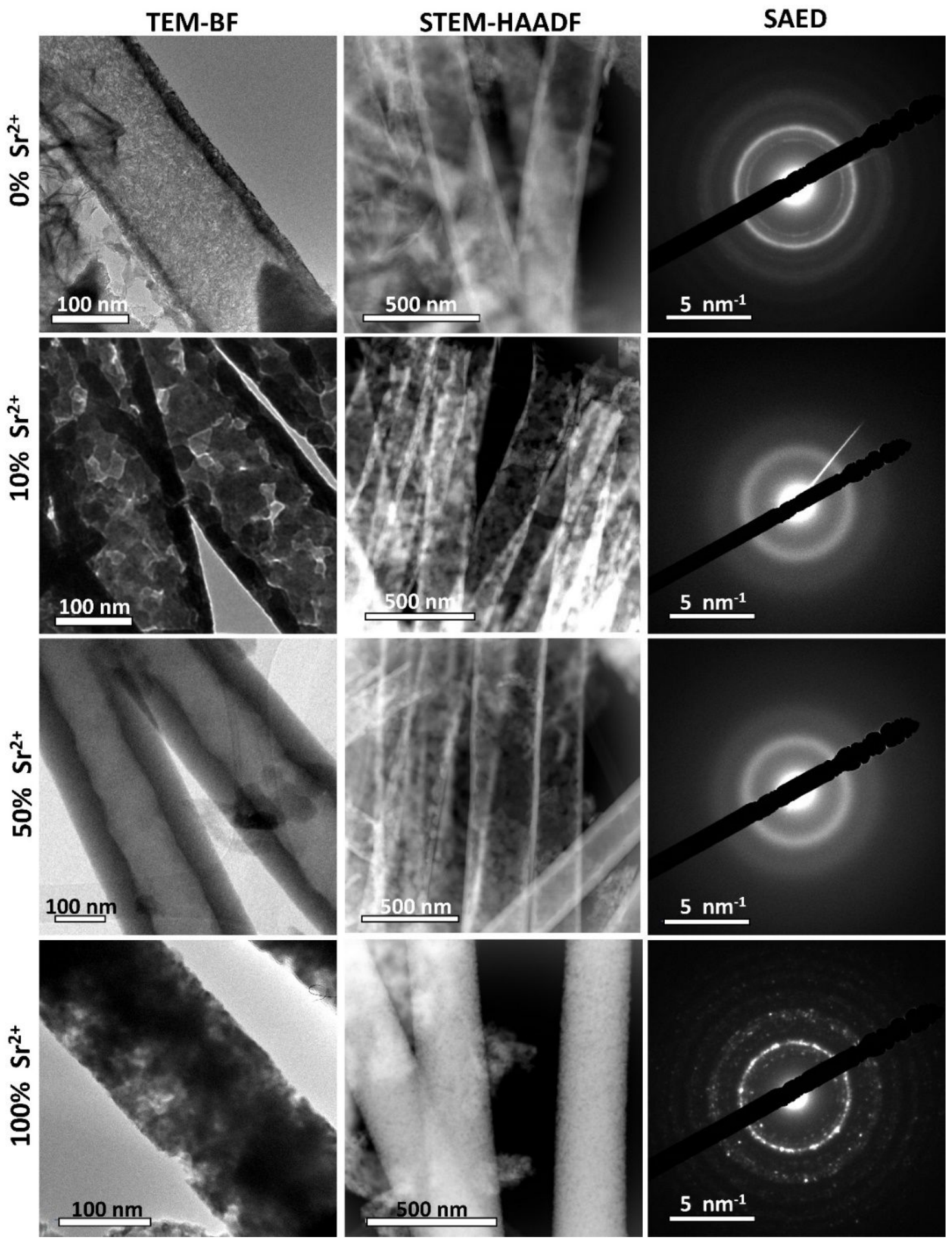

Figure 3.TEM-BF, STEM-HAADF images and SAED patterns of the $0,10,50$, and $100 \% \mathrm{Sr}^{2+}$

4 nanotubes. STEM-HAADF images show that the $0 \% \mathrm{Sr}^{2+}, 10 \% \mathrm{Sr}^{2+}$ and $50 \% \mathrm{Sr}^{2+}$ nanotubes are

5 hollow. The absence of crystalline reflections in the SAED patterns of the $10 \% \mathrm{Sr}^{2+}$ and $50 \%$

$6 \mathrm{Sr}^{2+}$ nanotubes confirms their amorphous character depicted by XRD. 


\subsection{Nanoscale Analysis by Electron Energy Loss Spectromicroscopy (EELS)}

2

The chemical composition of the nanotubes was investigated with nanometric resolution by EELS. STEM-EELS offers the advantage of spatial resolution and has been used as powerful technique in biomineralization and biomaterials investigations.

The spectra in Figure 4a exhibit the Sr-L (ca. 1950 eV) and P-K (ca. $2150 \mathrm{eV}$ ) edges averaged over typically $100 \mathrm{~nm}$ x $100 \mathrm{~nm}$ surface area. The $\mathrm{Sr} / \mathrm{P}$ intensities drastically change as $\mathrm{Ca}^{2+}$ is substituted by $\mathrm{Sr}^{2+}$ in the samples. Quantifications can be done and typical $\mathrm{Sr} / \mathrm{P}$ ratios of $0,0.16,0.8$ and 1.7 are obtained in agreement with the expected composition within the 10\% EELS accuracy. The EELS edges at lower energy, also obtained with ca. $100 \mathrm{~nm}$ of spatial resolution, are displayed in Figure 4b. A clear change of $\mathrm{Ca} \mathrm{L}$ (ca. $350 \mathrm{eV}$ ) intensity is observed as the amount of $\mathrm{Sr}^{2+}$ increases in the samples. On the other hand, the P-L and Sr-M edges are overlapping giving a cumbersome situation where no reliable quantification can be done. STEMEELS were also done with nanometer scale resolution by acquiring spectromicroscopic images or lines across the apparent walls of the hollow structures (Figure 4c). To achieve such spatial resolution, electron doses have to be increased and the overall SNR ratios of the EELS signal get lower. With such conditions, no quantifications have been done, even for the non-overlapping edges. We focus on the 50\% $\mathrm{Sr}^{2+}$ amorphous nanotubes where heterogeneities have been robustly measured, notably on the sidewall of the tube. The analysis of Sr-L and P-K edges indicated that the outer surface of the tube (the surface that grows at the interface with the pore) is phosphorus enriched (Figure 4d). With the lower energy edges (figure 4e), it is not possible to differentiate between $\mathrm{P}$ and $\mathrm{Sr}$, but comparing with the $\mathrm{Ca}-\mathrm{L}$ distribution, heterogeneities are present throughout the tube wall. The $\mathrm{Sr}$ and $\mathrm{Ca}$ distribution do not have maximum intensity at 
1 the same position and, in particular a clearer $\mathrm{Ca}$ enriched layer at the inner surface of

2 the tube is observed. Furthermore, both surfaces show the presence of additional C-

3 layers. Such carbon layers are often present in STEM-EELS experiments and might be

4 due to contamination during the STEM experiments or the sample preparation.

5 Additional EELS experiments have been done keeping the sample near $\mathrm{LN}_{2}$

6 temperature, that is known to strongly reduce contamination and degradation issues, and

7 similar carbon rich layers of several $\mathrm{nm}$ have been detected in the outer surface (Figure

8 S7). The presence of carbonate groups can be observed by EELS since its spectroscopic

9 C-K fine structure is different from the one of amorphous carbon (or contamination

10 carbon or heavily damage organic carbon). As shown in Figure S7d, carbonate ions are

11 present in the $\mathrm{Sr}(\mathrm{ACP})$, and at the Ca enriched layer at the inner surface. On the other

12 hand, the carbon layer on the outer surface has a broader spectroscopic structure and

13 might be the beam damaged PAA. These STEM-EELS results clearly evidence

14 heterogeneities from the outer to the inner part of the hollow tubes whose might origin

15 from the precipitation into confined mesoporous cavity.

16 

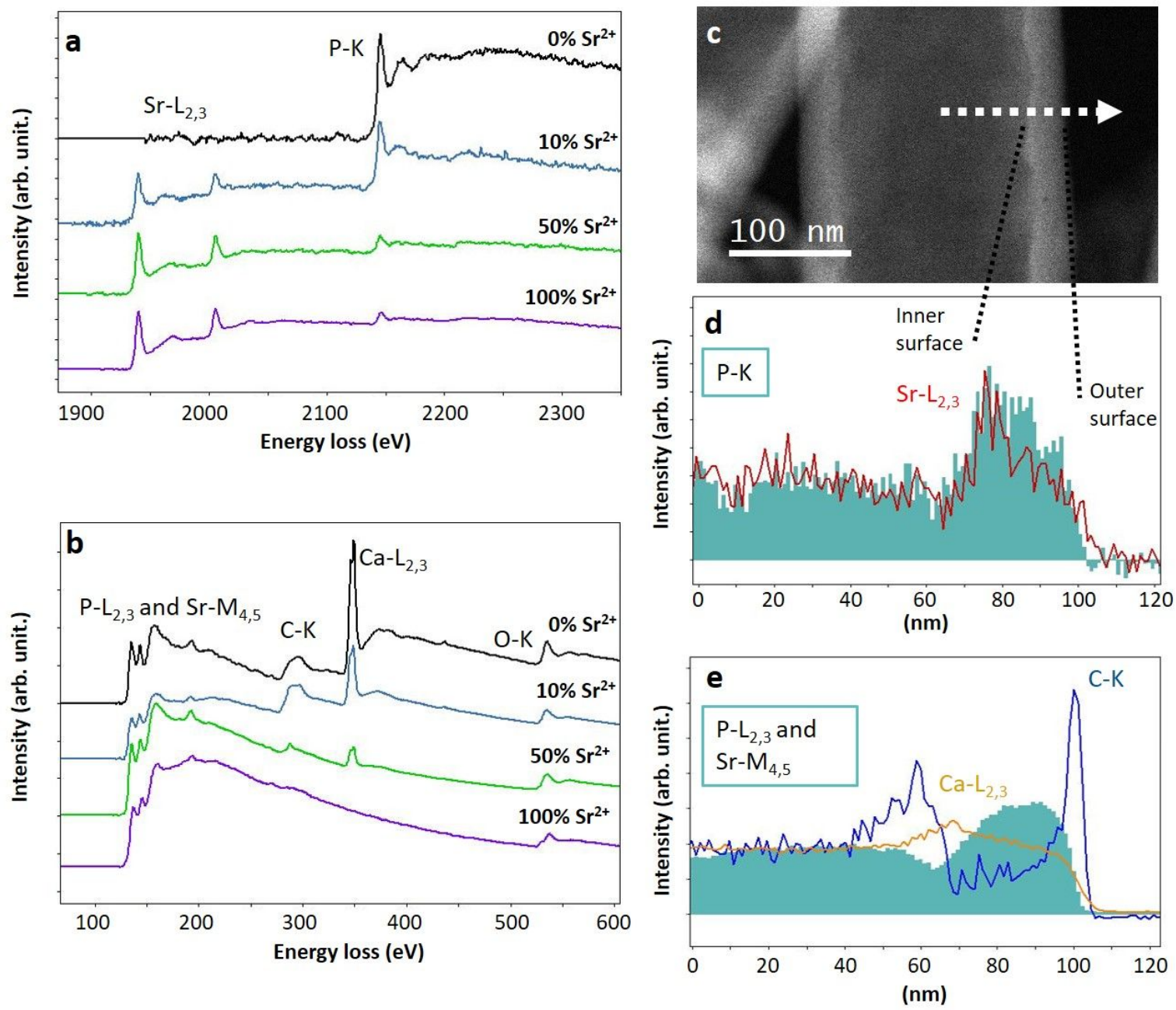

3 Figure 4. (a,b) EELS spectra of the tubes containing $0 \% \mathrm{Sr}^{2+}, 10 \% \mathrm{Sr}^{2+}, 50 \% \mathrm{Sr}^{2+}$ and $100 \% \mathrm{Sr}^{2+}$.

4 (c,d,e) EELS spectromicroscopy performed on the $50 \% \mathrm{Sr}^{2+}$ nanotube showing the presence of

5 several compositional heterogeneities. 


\section{$2 \quad 3.3$ Formation mechanism of $\operatorname{Sr}(\mathrm{CaP})$ nanotubes}

3

4 a marked effect over the formation $\mathrm{CaP}$ particles in terms of size, morphology, and

5 selection of mineral phase. For instance, while the most reported morphology of ACP is

6 spherical, here we were able to tailor the shape of $\operatorname{Sr}(\mathrm{ACP})$ into tubes thanks to the

7 boundary offered by the membrane pores which in turn direct the mineral growth. ${ }^{32}$

8 Likewise, the nanometric apatite crystals precipitated in absence of $\mathrm{Sr}^{2+}$ assembled into

9 tubes, rather than the usually spherulitic morphology. ${ }^{31}$ Interestingly, while collagen is

10 reported to define the structural features of bone mineral, biomimetic apatite was

11 formed here only by using physical confinement.

12 Recently, we have shown that the biomimetic precipitation of $\operatorname{Sr}(\mathrm{ACP})$ in

13 homogeneous media starts when the degree of $\mathrm{Ca}^{2+}$ substitution by $\mathrm{Sr}^{2+}$ reaches $25 \%$ in

14 the crystalline lattice of apatite. ${ }^{32}$ However, this amorphous phase was stabilized in the

15 reaction medium only at higher degrees of $\mathrm{Sr}^{2+}$ substitution, namely 50 and $75 \%$. Here,

16 by controlling the physical environment where the precipitation takes place, $\operatorname{Sr}(\mathrm{ACP})$

17 was formed at lower amounts of $\mathrm{Sr}^{2+}$, i.e. $10 \% \mathrm{Sr}^{2+}$, that is the maximum percentage of

18 this ion found in the bone tissue. ${ }^{35}$ EDX analysis confirmed that this effect was provided

19 by the physical confinement since the amount of $\mathrm{Sr}^{2+}$ incorporated into the products

20 formed in bulk and within the pores of the membranes was similar. Relying on the 21 pathway of apatite formation in vitro and previous findings, we hypothesize that $\mathrm{Sr}^{2+}$ 22 acts as kinetic stabilizing agent of ACP during apatite formation. ${ }^{36,37}$ As previous

23 reported, one hypothesis is that the confinement provided by the membrane pore 24 reduces the contact of the particles with the solution thus hindering redissolution and reprecipitation processes towards crystallization. ${ }^{38}$ Actually, the study of the lifetime of 
1 different amorphous minerals within limited volumes revealed several mechanisms by

2 which confinement may affect the kinetics of precipitation, including slower transport

3 of ions and reduced convection. ${ }^{39-41}$ In any case, the role of confinement is made clear

4 by the presence of nanoscale heterogeneities from the outer to the inner surfaces of the

5 tubes, some of the possible origin being the slower transport of ions, and preferential

6 local dissolution and precipitation.

7 The stabilization of $\operatorname{Sr}(\mathrm{ACP})$ in confinement at $\mathrm{Sr}^{2+}$ content close to that found

8 in the tissue of animals raises interesting questions concerning its impacts on bone

9 biomineralization. Previous observations have pointed out that ACP infiltrates within

10 the confines of the gap zone in collagen to form bone mineral. ${ }^{42,43}$ Notably, higher $\mathrm{Sr}^{2+}$

11 concentrations are found in young bone which is reported to be less crystalline as

12 compared to the long term bone. ${ }^{44,45} \mathrm{On}$ account of that, our results bring the notion that

$13 \mathrm{Sr}^{2+}$ impacts on the early stages of bone mineralization as proposed for $\mathrm{Zn}^{2+}$ and non-

14 collagenous proteins. ${ }^{46,47}$ Therefore, the role of $\mathrm{Sr}^{2+}$ on bone apatite may be further than

15 a simple hetero-ionic exchange with $\mathrm{Ca}^{2+}$ or physical adsorption in the mature mineral,

16 as usually described ${ }^{48}$ However, it is important to note that the mineralization in vitro is

17 a simplified model of the much more complex biological systems, in which a multitude

18 of specialized molecules and cells are involved in this process. 


\section{3.4. In vitro remineralization and $\mathrm{Sr}^{2+}$ release evaluation}

3

Aiming at bone tissue regeneration, the bioactivity of the nanotubes was assessed in vitro by immersion in SBF, a solution which mimics the blood serum in terms of ionic composition and $\mathrm{pH}$. This is a standard assay to give insights towards the bone forming ability of biomaterials in vitro under physiological conditions. ${ }^{24}$

$\mathrm{XRD}$ revealed that the particles induced the precipitation of biomimetic apatite with typical broad diffraction peaks after 5 days of immersion in SBF (Figure $5 b$ ). It should be noted that $\mathrm{SrCO}_{3}$ was formed in addition to apatite in the $50 \% \mathrm{Sr}^{2+}$ sample, as indicated by the diffraction peaks at $2 \theta=25^{\circ}$ and $35^{\circ}$ (indicated by $\mathrm{S}$ in the diffractogram). As discussed, this sample is likely formed by a mixture of $\operatorname{Sr}(\mathrm{ACP})$ and Sr(ACC). Therefore, in SBF these mineral phases undergo crystallization leading to the formation of apatite and $\mathrm{SrCO}_{3}$. Interestingly, $\mathrm{SrCO}_{3}$ is also a potential biomaterial to osteoporosis treatments, thus, the present experimental conditions and setup could constitute an alternative procedure to precipitate such mixed phases in vitro..$^{33,49}$

SEM images show that the nanotubes were covered by a newly rough layer formed by nanometric platelets confirming the deposition biomimetic apatite (Figure 5a). The fact that the morphology of the nanotubes was maintained, and their diameter increased after the exposure to SBF shows that they acted as template for the nucleation of the new phase, i.e. biomimetic apatite. This result also evidenced that the remineralization was spatially controlled, which is important to avoid pathological calcification in vivo. It is proposed that $\mathrm{Ca}^{2+}$ and $\mathrm{PO}_{4}{ }^{3-}$ from $\mathrm{SBF}$ accumulate at the surface of templates leading to the formation of ACP which by redissolution and reprecipitation processes is converted into apatite, the most thermodynamically stable phase of $\mathrm{CaP}$ at physiological conditions. ${ }^{42,36}$ Then, apatite grows spontaneously by 
1 consuming the templating particles and the ions from the medium including $\mathrm{Na}^{+}, \mathrm{Mg}^{2+}$ 2 and $\mathrm{CO}_{3}{ }^{2-}$, evolving towards a bone-like mineral in terms of morphology and 3 composition. ${ }^{50}$ The incorporation of $\mathrm{Sr}^{2+}$ did not disturb the apatite-forming ability of

4 the tubes during the period of exposure investigated herein, in agreement with previous 5 findings. ${ }^{51}$ Hence, these results confirm the potential of these particles to induce 6 biomimetic remineralization in physiological environment.

7 The ability of the particles to release $\mathrm{Sr}^{2+}$ in the cell culture medium was 8 evaluated for 1, 3, 7, 14 and 21 days (Figure 5c). The amount of $\mathrm{Sr}^{2+}$ increased with the 9 time suggesting the sustained and controlled delivery for long periods. This is an 10 important result as most of the materials are reported to release the total amount of $\mathrm{Sr}^{2+}$ 11 within few days. It is noteworthy that the $50 \% \mathrm{Sr}^{2+}$ sample released higher amount of $12 \mathrm{Sr}^{2+}$ until the $14^{\text {th }}$ day compared to the $100 \% \mathrm{Sr}^{2+}$ sample. This is likely ascribed to the 13 amorphous nature of the $50 \% \mathrm{Sr}^{2+}$ sample which may be more soluble than the highly 14 crystalline $100 \% \mathrm{Sr}^{2+}$ sample. It is worth mentioning that $\mathrm{SrCO}_{3}$ also contributes to the 15 sustained release of $\mathrm{Sr}^{2+}$ since in physiological environment this mineral is 16 progressively converted into biomimetic apatite by redissolution and reprecipitation as 17 previously reported. ${ }^{33}$ After long periods, the concentrations found in the solutions fall 18 within the $\mathrm{Sr}^{2+}$ level in the serum of patients treated with strontium ranelate in which 19 bone healing was achieved in the range of $2-18 \mathrm{mg} \mathrm{L}^{-1} .^{20}$ These results also show that 20 the composition of the particles can be tailored to release an appropriate level of $\mathrm{Sr}^{2+}$ 21 according to the application. 
a

$0 \% \mathrm{Sr}^{2+}$

$10 \% \mathrm{Sr}^{2+}$

$50 \% \mathrm{Sr}^{2+}$

$100 \% \mathrm{Sr}^{2+}$
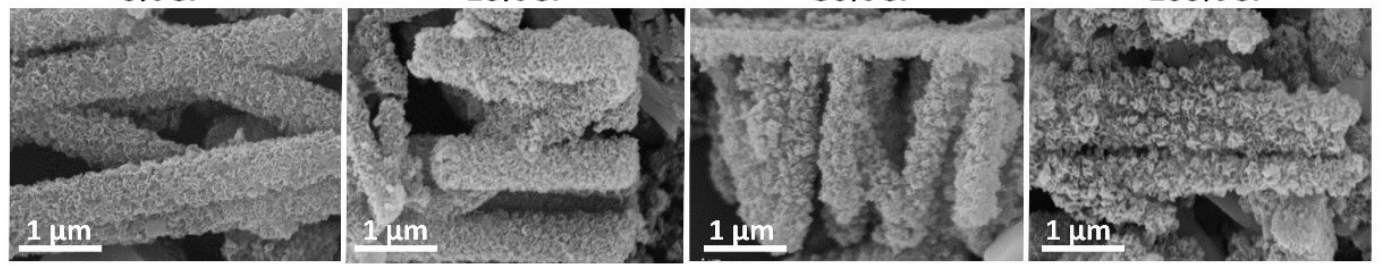

b

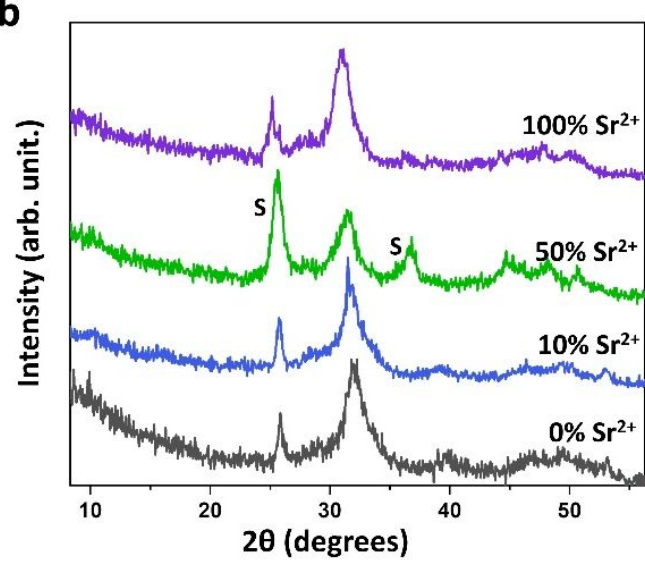

C

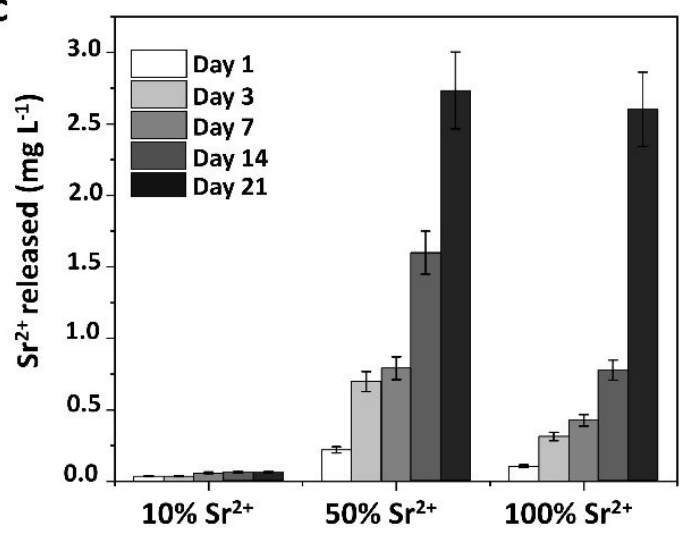

2 Figure 5. (a) SEM images and (b) X-ray diffraction patterns of the tubes containing different 3 amounts of $\mathrm{Sr}^{2+}$ after 5 days of immersion into SBF. The diffractograms were indexed with the 4 hydroxyapatite structure (JCPDS 9-432). The 50\% $\mathrm{Sr}^{2+}$ sample led to the additional formation 5 of $\mathrm{SrCO}_{3}$ as observed by the additional peaks at $2 \theta=25^{\circ}$ and $35^{\circ}$ (indicated by $\mathrm{S}$ in the 6 diffractogram). (c) $\mathrm{Sr}^{2+}$ released from the 10\% $\mathrm{Sr}^{2+}, 50 \% \mathrm{Sr}^{2+}$ and $100 \% \mathrm{Sr}^{2+}$ tubes immersed in 7 the cell culture medium at $37{ }^{\circ} \mathrm{C}$ for 12 hours, 1, 3, 7, 14 and 21 days. The amount of $\mathrm{Sr}^{2+}$ 8 released by the particles falls in the therapeutic doses used for osteoporosis treatment. 
1 3.5. In vitro assessment of cytocompatibility of $\mathrm{Sr}(\mathrm{CaP})$ nanotubes

2

It is well-kwon that an imbalance in the activity of osteoblasts and osteoclasts leads to bone diseases, in special osteoporosis. In this sense, the biological response of the particles was assessed in vitro by using pre-osteoblastic cells and osteoclasts differentiation protocols. ${ }^{52}$

Confocal microscopy images obtained after 7 days of culture confirm that MC3T3-E1 cells reached confluence displaying a polygonal shape typical from osteoblasts (Figure 6a). ${ }^{53}$ SEM images obtained after long term culture (21 days) show that cells remained attached to the substrate with flattened and elongated morphology characteristic of mature osteoblasts (Figure 6b). Moreover, the continuous monolayers of cells indicates that the particles did not disturb their adhesion and proliferation. ${ }^{54}$ MTT assays obtained after 21 days of culture confirmed that the particles did not significantly influence MC3T3-E1 viability compared to the control, attesting to their negligibly toxicity towards osteoblasts at the concentration used here, even after long exposure periods (Figure 6c). It has been reported that concentrations of $\mathrm{Sr}^{2+}$ close to 17 $\mathrm{mg} \mathrm{L}^{-1}$ (or higher) are needed to increase the osteoblasts proliferation which is higher than the range investigated herein and found in the plasma of humans treated with strontium ranelate $\left(\sim 10 \mathrm{mg} \mathrm{L}^{-1}\right) .{ }^{55,56} \mathrm{Still}$, it is important to emphasize that $\mathrm{Sr}^{2+}$ may accumulate in the bone tissue provoking pathological calcification. ${ }^{17,57}$ Therefore, low doses are preferred in $\mathrm{Sr}^{2+}$-based therapies. In fact, osteoblasts viability is only the initial parameter to be evaluated during mineralization studies.

We further investigated the impacts of the particles on the ALP activity, an important marker of osteogenic activity and therefore bone formation. ${ }^{58}$ After 7 days of culture the ALP activity was higher to $10 \% \mathrm{Sr}^{2+}$ and $50 \% \mathrm{Sr}^{2+}$ while there were no significative differences between $0 \% \mathrm{Sr}^{2+}$ and $100 \% \mathrm{Sr}^{2+}$ compared to the control 
1 (Figure 6d). ALP activity is an early indicator of osteoblast phenotype differentiation,

2 therefore the increased ALP activity on day 7 for cells cultured in the presence of the

$3 \quad 10 \%$ and $50 \% \mathrm{Sr}^{2+}$ particles suggests higher osteogenic differentiation as compared to

4 the pure $0 \%$ and $100 \% \mathrm{Sr}^{2+}$ particles. Likewise, a recent investigation reporting on the

5 treatment of osteoblasts with a $\mathrm{Sr}^{2+}$-flavonoid complex revealed that the increased ALP

6 activity in the presence of $\mathrm{Sr}^{2+}$ can be associated to the overexpression of the enzyme

7 whereas the cell viability was maintained. ${ }^{59}$ Moreover, these results are in line with in

8 vivo and in vitro studies showing that $\mathrm{Ca}^{2+}$ and $\mathrm{Sr}^{2+}$ mixed may led to an ideal

9 microenvironment where these ions act synergistically to stimulate osteoblast

10 metabolism at the early stages of differentiation. ${ }^{49,60}$ Indeed, the synergism between $\mathrm{Sr}$

11 and other elements such $\mathrm{Fe}$ and $\mathrm{Cu}$ in promoting bone mineral formation has been

12 demonstrated. ${ }^{61-63}$ It is noteworthy that the replacement of $\mathrm{Ca}^{2+}$ by $\mathrm{Sr}^{2+}$ is reported to

13 enhance the degradability of phosphates. In this regard, it has been speculated that $\mathrm{Sr}^{2+}$

14 substitution in apatite might additionally provide an ion-rich environment conducive for

15 osteogenesis. ${ }^{60,64,66,67}$

16 In general, the ALP activity increased after 14 days of culture, as already

17 described for osteoblast-like cells. ${ }^{26}$ This strengths the particles ability to support

18 MC3T3-E1 cells evolution towards mature bone-forming osteoblasts. Finally, Alizarin

19 Red S assays revealed that the mineralization of extracellular matrix by osteoblasts was

20 not negatively affected by the presence of the particles (Figure 6e and Figure S8).

21 Although no statistical significance was found between the samples, a tendency of

22 increased mineralization was observed for the $10 \% \mathrm{Sr}^{2+}$ and $50 \% \mathrm{Sr}^{2+}$ samples as

23 compared to the control in agreement with ALP results. Overall, the activity of MC3T3-

24 E1 cells was sustained in the presence of the particles strengthening their potential

25 application as platform to induce positive osteoblast responses at low doses. 


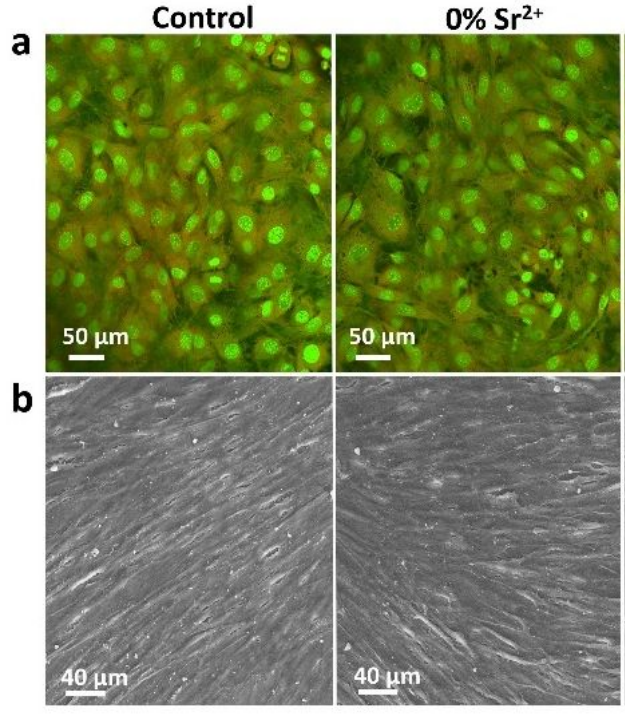

c

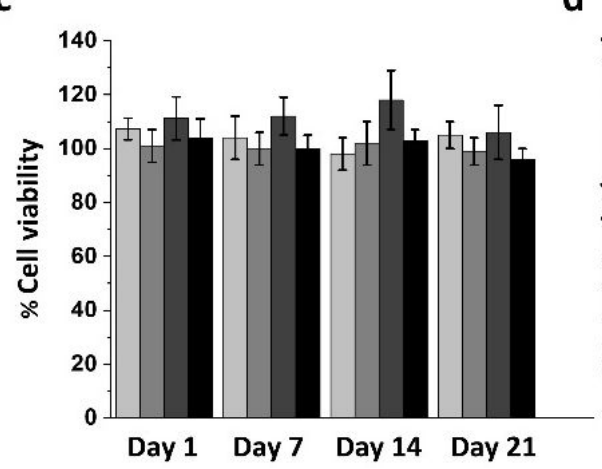

d
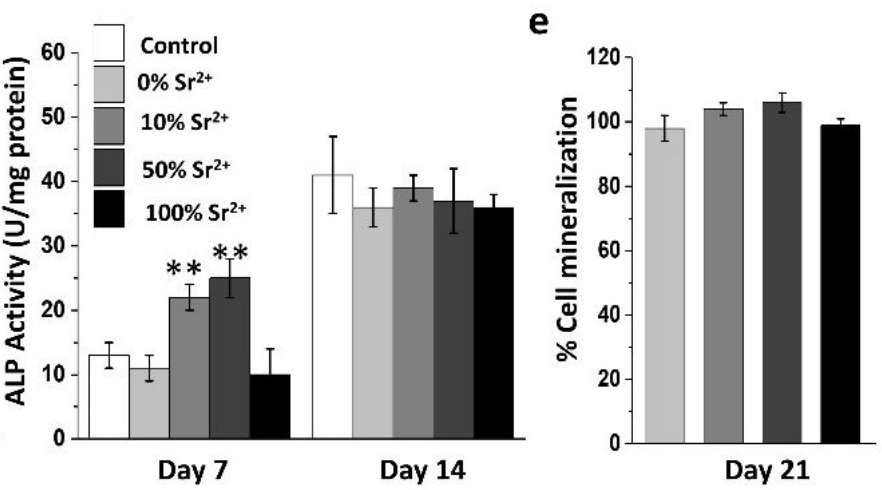

6 Figure 6. (a) Confocal microscopy and (b) SEM images of MC3T3-E1 cells cultured for 7 and

721 days respectively, in the absence (control) and in the presence of $\operatorname{Sr}(\mathrm{CaP})$ nanotubes 8 containing $0 \% \mathrm{Sr}^{2+}, 10 \% \mathrm{Sr}^{2+}, 50 \% \mathrm{Sr}^{2+}$ and $100 \% \mathrm{Sr}^{2+}$. (c) Cell viability versus control 9 measured by MTT assay after 24 h, 7, 14 and 21 days of culture, (d) activity of ALP in the 10 osteoblasts' membrane fraction after 7 and14 days of culture and (e) quantification of 11 mineralized nodules formed in the wells after 21 days of culture. Results represent the mean 12 values \pm standard deviation for triplicate determination for each experiment. Multiple statistical 13 comparisons were performed by two-way ANOVA, $* * \mathrm{p}<0.01$. 
1

2

3 function. Bone marrow-derived monocytes/macrophages (BMMs) were cultured under

4 osteoclastogenic condition medium in the presence of the $0,10,50$ and $100 \% \mathrm{Sr}^{2+}$

5 nanotubes and TRAP staining was performed to identify osteoclasts differentiation. The

6 formation of multinucleated osteoclasts was inhibited by the $\mathrm{Sr}^{2+}$ loaded particles

7 whereas no significant differences in relation to the control were found to the $0 \% \mathrm{Sr}^{2+}$

8 particles (Figure 7a). Quantitative measurement confirmed that the number of TRAP

9 positive cells was reduced as the $\mathrm{Sr}^{2+}$ concentration increased in the particles (Figure

7b). To evaluate the ability of the tubes to inhibit bone resorption, osteoclasts were cultured now on hydroxyapatite-coated plates and in the presence of the particles containing different amounts of $\mathrm{Sr}^{2+}$. The formation of demineralization pits was prevented by the $\mathrm{Sr}^{2+}$ loaded particles (Figure 8a). Quantification of the areas of the pits confirmed that the demineralization capacity of osteoclasts was significantly reduced by the $10 \% \mathrm{Sr}^{2+}$ particles or completely inhibited in the case of the $50 \% \mathrm{Sr}^{2+}$ and $100 \%$ $\mathrm{Sr}^{2+}$ particles (Figure $8 \mathrm{~b}$ ).

Overall, these results are in agreement with previous investigations which demonstrated that $\mathrm{Sr}^{2+}$ released from biomaterials and particles inhibit osteoclast differentiation and resorption activities. ${ }^{69}$ Nevertheless, $\mathrm{Sr}^{2+}$ levels much higher $(88 \mathrm{mg}$ $\left.\mathrm{L}^{-1}\right)$ than those found in the serum of patients treated with strontium ranelate $\left(10 \mathrm{mg} \mathrm{L}^{-1}\right)$ are usually described for eliciting such anti-osteoclastogenic effects. ${ }^{70}$ Herein, a low amount of $\mathrm{Sr}^{2+}$ (less than $0.2 \mathrm{mg} \mathrm{L}^{-1}$ ) was enough to significantly hinder osteoclast activity and differentiation. Interestingly, the $\% \mathrm{Sr}^{2+}$ incorporated in these particles is in the physiological percentage found in bone tissue $\left(10 \%\right.$ mol with respect to $\left.\mathrm{Ca}^{2+}\right){ }^{63}$ Even the highest $\mathrm{Sr}^{2+}$ concentration used here $\left(0.7 \mathrm{mg} \mathrm{L}^{-1}\right)$ was lower than that used in other investigations reporting on bioglasses able to delivery $\mathrm{Sr}^{2+}$ within the range 
1 described as efficient to trigger antiosteoporotic effects in vivo $\left(\sim 5 \mathrm{mg} \mathrm{L}^{-1}\right) .{ }^{19}$ This is an

2 important feature, as the side effects of $\mathrm{Sr}^{2+}$ accumulation in bone cannot be overlooked;

3 although high doses decrease differentiation and metabolism of osteoclasts it may also

4 lead to pathological mineralization. ${ }^{17,17}$ Actually, the regulation of bone cells

5 metabolism by $\mathrm{Sr}^{2+}$ is quite ambiguous. Several studies have demonstrated that

6 osteoblasts response to $\mathrm{Sr}^{2+}$ might be a question of optimal environment rather than a

7 concentration driven effect. ${ }^{49,62}$

8 On the basis of our results and the literature presented in this discussion, we

9 believe that tuning the $\mathrm{Sr}^{2+}$ and $\mathrm{Ca}^{2+}$ concentrations is crucial for the design of materials

10 to bone regeneration and the approach described herein provides an effective way to do 11 this.

12

13

14

15

16

17

18

19 


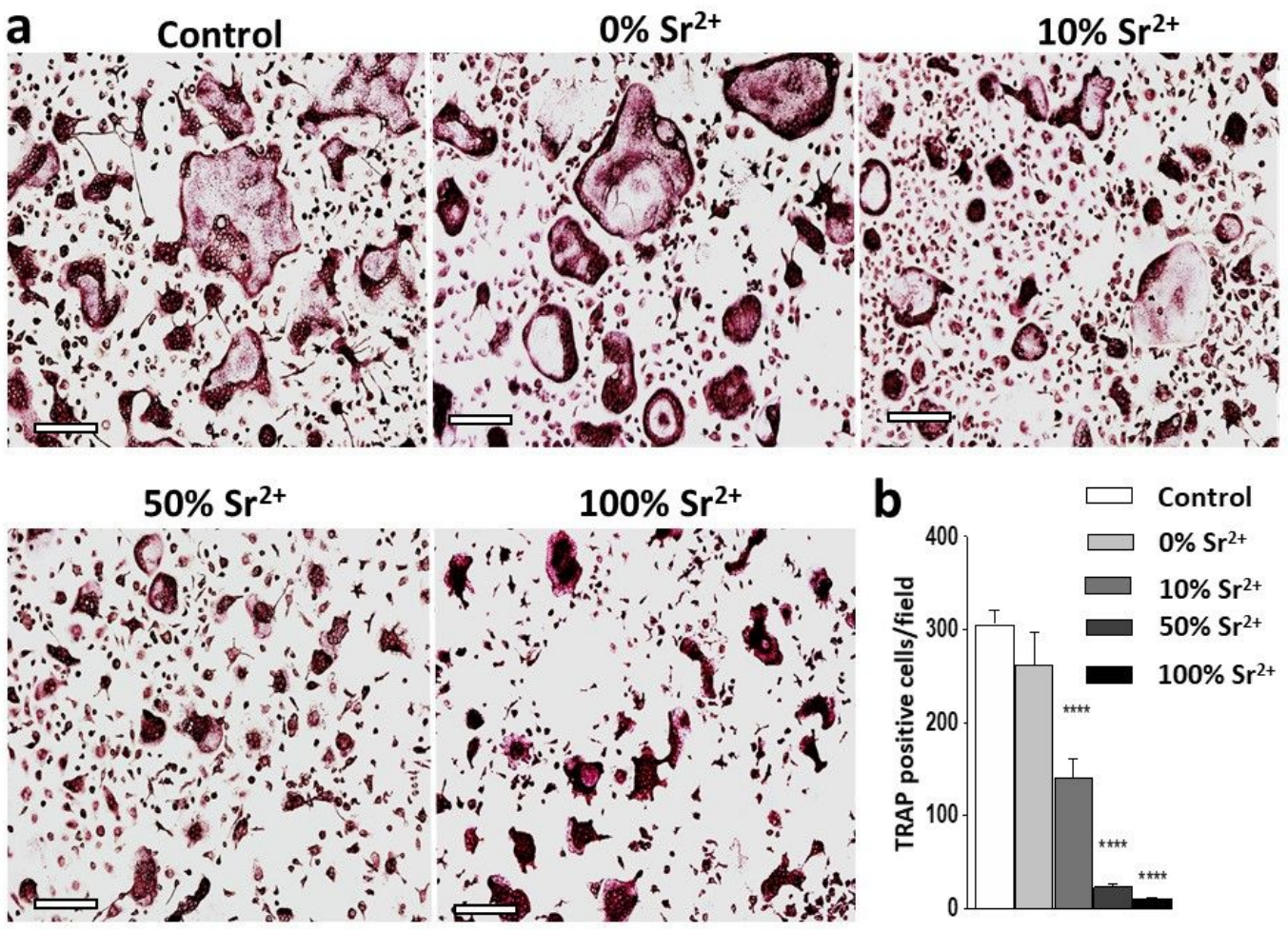

2 Figure 7. (a) Representative images and (b) quantification of TRAP-positive osteoclasts 3 cultured for 4 days. Bone marrow macrophages (BMMs) was cultured under M-CSF and 4 RANKL stimulation, in the absence (control) and in the presence of the $\operatorname{Sr}(\mathrm{CaP})$ tubes 5 containing $0 \% \mathrm{Sr}^{2+}, 10 \% \mathrm{Sr}^{2+}, 50 \% \mathrm{Sr}^{2+}$ and $100 \% \mathrm{Sr}^{2+}$. Results represent the mean value \pm 6 standard deviation $(n=5)$ representative of two independent experiments. One-way ANOVA, 7 followed by Tukey's post-test.**** $\mathrm{p}<0.001$, compared to control. Scales bars represent 100 $8 \mu \mathrm{m}$. 


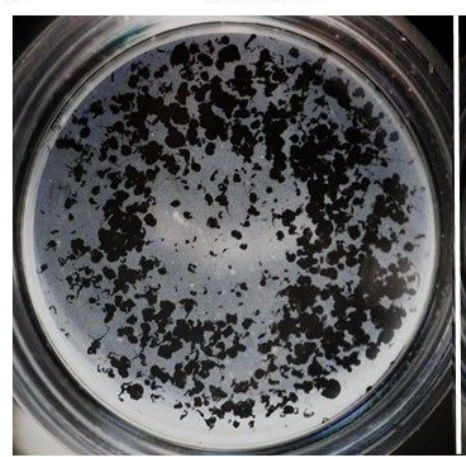

$0 \% \mathrm{Sr}^{2+}$

$10 \% \mathrm{Sr}^{2+}$
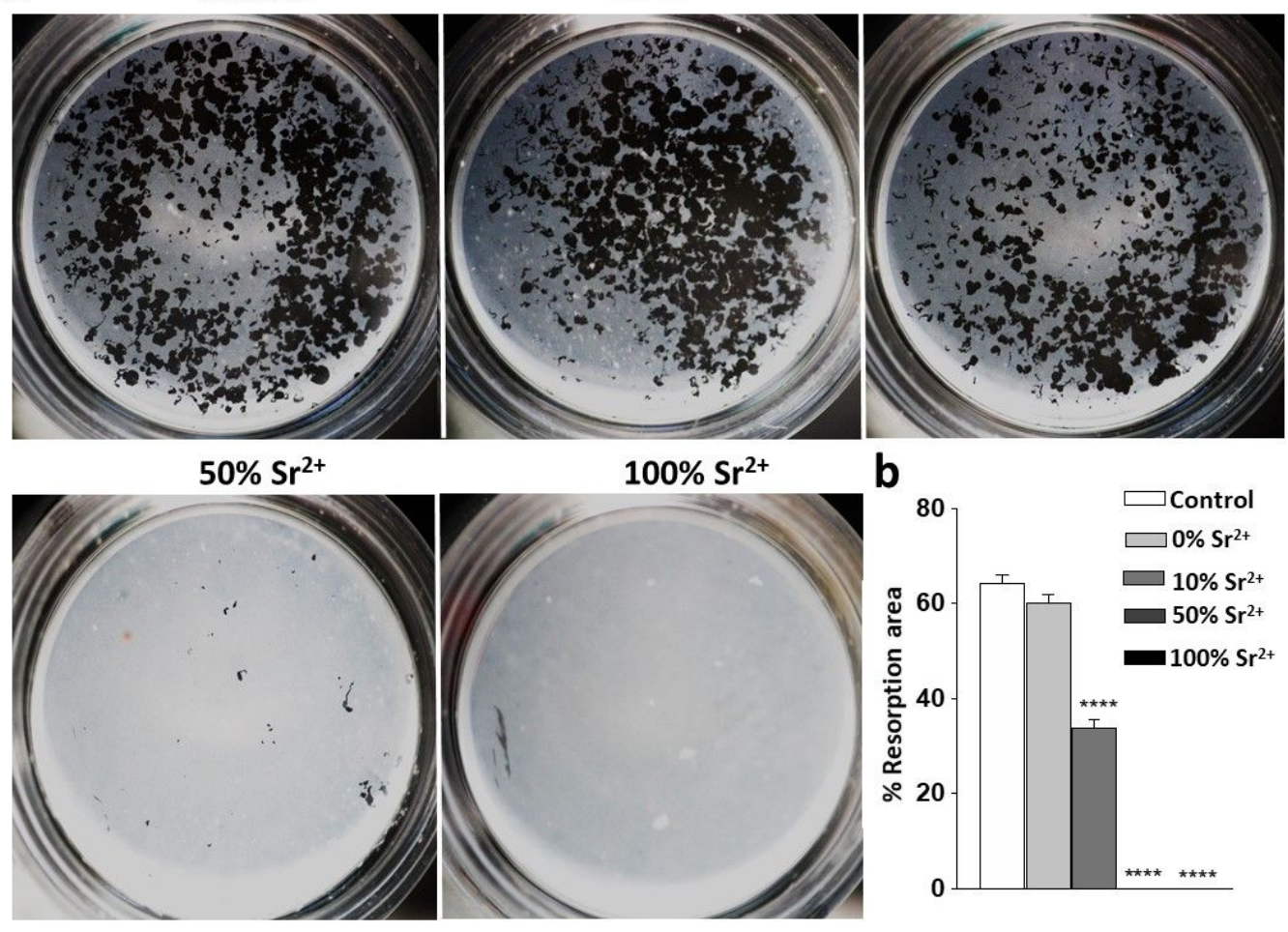

b

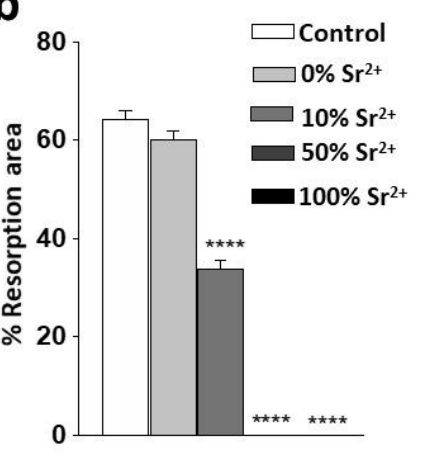

3 Figure 8. (a) Representative images and (b) quantification of resorption area induced by 4 osteoclasts cultured in hydroxyapatite-coated plates for 5 days. Bone marrow macrophages 5 (BMMs) was cultured under M-CSF and RANKL in hydroxyapatite-coated plates, in the 6 absence (control) and in the presence of $\mathrm{Sr}(\mathrm{CaP})$ tubes containing $0 \% \mathrm{Sr}^{2+}, 10 \% \mathrm{Sr}^{2+}, 50 \% \mathrm{Sr}^{2+}$ 7 and $100 \% \mathrm{Sr}^{2+}$. Results represent the mean value \pm standard deviation $(\mathrm{n}=5)$ representative of 8 two independent experiments. One-way ANOVA, followed by Tukey's post-test.****p $<0.001$, 9 compared to control. 


\section{4. CONCLUSIONS}

3

A bioinspired approach relying on physical confinement was developed to form

$5 \mathrm{Sr}(\mathrm{CaP})$ nanotubes suitable to be used as building blocks of bone. In contrast to

6 previous investigations, biomimetic platelets of apatite were formed here without the

7 need of collagen, thus representing an innovative way to form fibril-like biomimetic

8 biomaterials. The combination of $\mathrm{Sr}^{2+}$ and $\mathrm{CaP}$ yielded multifunctional particles able to

9 induce osteoblasts proliferation, biomimetic remineralization and to reduce the

10 differentiation and resorption activity of osteoclasts. Moreover, the increased ALP

11 activity found for the $10 \% \mathrm{Sr}^{2+}$ and $50 \% \mathrm{Sr}^{2+}$ samples supports their positive effect on

12 the cell maturation and mineralization. Different from the current therapies, all these

13 fundamental aspects for bone regeneration were triggered simultaneously here, and

14 most importantly at low doses of $\mathrm{Sr}^{2+}$ which is crucial to avoid its side effects. By

15 showing that $\mathrm{Sr}^{2+}$ can be effective at low concentrations when combined with CaPs, this

16 investigation reconciliates the reports of pathological mineralization at excess of $\mathrm{Sr}^{2+}$

17 with its therapeutic effects. Going further, this investigation provides a facile strategy to

18 produce a new generation of biomimetic ceramics with relevant biological responses. 


\section{ACKNOWLEDGMENTS}

2

C.B. Tovani thanks FAPESP (2014/24249-0) for the scholarships. A.P. Ramos and P. Ciancaglini thank FAPESP for research grants (2017/08892-9 and 2016/212360). We also thank Marcos A. E. Cruz and Lucas B. Nogueira for the support with cell culture experiments. P. Ciancaglini and A.P. Ramos are CNPq researchers.

\section{ASSOCIATED CONTENT}

SEM images of the track-etched polycarbonate membrane; SEM images of submicrometer tubes formed using $400 \mathrm{~nm}$ pore-size track-etched membranes; Determination by TEM-EDX of the $\mathrm{Sr}^{2+}$ content in the particles formed in bulk and

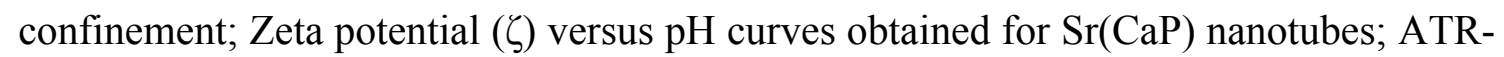
FTIR spectra of $\mathrm{Sr}(\mathrm{CaP})$ nanotubes, STEM-HAADF image of $10 \% \mathrm{Sr}^{2+}$ nanotube; TEM-EDX mapping images of $10 \% \mathrm{Sr}^{2+}$ and $50 \% \mathrm{Sr}^{2+}$ nanotubes; STEM-EELS spectra obtained at low temperature by $\mathrm{LN}_{2}$ sample holder of $50 \% \mathrm{Sr}^{2+}$ nanotube; Photographs of Alizarin Red S stained osteoblasts' cultures.

\section{REFERENCES}

(1) de Melo Pereira, D.; Habibovic, P. Biomineralization-Inspired Material Design for Bone Regeneration. Adv. Healthc. Mater. 2018, 7 (22), 1-18.

(2) Reznikov, N.; Bilton, M.; Lari, L.; Stevens, M. M.; Kröger, R. Fractal-like Hierarchical Organization of Bone Begins at the Nanoscale. Science. 2018, 360, No. eaao2189.

(3) Liu, J.; Yu, P.; Wang, D.; Chen, Z.; Cui, Q.; Hu, B.; Zhang, D.; Li, Y.; Chu, H.; Li, J. Wood-Derived Hybrid Scaffold with Highly Anisotropic Features on Mechanics and Liquid Transport toward Cell Migration and Alignment. ACS Appl. Mater. Interfaces 2020, 12 (15), 17957-17966.

(4) Glimcher, M. J. Bone: Nature of the Calcium Phosphate Crystals and Cellular, Structural, and Physical Chemical Mechanisms in Their Formation. Rev. Mineral. Geochemistry 2006, 64 (1), 223-282.

(5) Habraken, W.; Habibovic, P.; Epple, M.; Bohner, M. Calcium Phosphates in Biomedical Applications: Materials for the Future? Mater. Today 2016, 19 (2), 69-87.

(6) Weiner, S.; Wagner, H. D. The Material Bone: Structure-Mechanical Function Relations. Annu. Rev. Mater. Sci. 1998, 28 (1), 271-298. 
Pek, Y. S.; Gao, S.; Arshad, M. S. M.; Leck, K. J.; Ying, J. Y. Porous Collagen-Apatite Nanocomposite Foams as Bone Regeneration Scaffolds. Biomaterials 2008, 29 (32), 4300-4305.

(8) Ramírez-Rodríguez, G. B.; Delgado-López, J. M.; Iafisco, M.; Montesi, M.; Sandri, M.; Sprio, S.; Tampieri, A. Biomimetic Mineralization of Recombinant Collagen Type I Derived Protein to Obtain Hybrid Matrices for Bone Regeneration. J. Struct. Biol. 2016, 196 (2), 138-146.

(9) Lin, K.; Wu, C.; Chang, J. Advances in Synthesis of Calcium Phosphate Crystals with Controlled Size and Shape. Acta Biomater. 2014, 10 (10), 4071-4102.

(10) Yao, S.; Lin, X.; Xu, Y.; Chen, Y.; Qiu, P.; Shao, C.; Jin, B.; Mu, Z.; Sommerdijk, N. A. J. M.; Tang, R. Osteoporotic Bone Recovery by a Highly Bone-Inductive Calcium Phosphate Polymer-Induced Liquid-Precursor. Adv. Sci. 2019, 6 (19), 1900683.

(11) Yuan, H.; Fernandes, H.; Habibovic, P.; De Boer, J.; Barradas, A. M. C.; De Ruiter, A.; Walsh, W. R.; Van Blitterswijk, C. A.; De Bruijn, J. D. Osteoinductive Ceramics as a Synthetic Alternative to Autologous Bone Grafting. Proc. Natl. Acad. Sci. U. S. A. 2010, 107 (31), 13614-13619.

(12) Marie, P. J. Strontium as Therapy for Osteoporosis. Curr. Opin. Pharmacol. 2005, 5 (6), 633-636.

(13) Bonnelye, E.; Chabadel, A.; Saltel, F.; Jurdic, P. Dual Effect of Strontium Ranelate: Stimulation of Osteoblast Differentiation and Inhibition of Osteoclast Formation and Resorption in Vitro. Bone 2008, 42 (1), 129-138.

(14) Dorozhkin, S. V. Calcium Orthophosphates: Occurrence, Properties, Biomineralization, Pathological Calcification and Biomimetic Applications. Biomatter 2011, 1 (2), 121164.

(15) Sun, W.; Fan, J.; Wang, S.; Kang, Y.; Du, J.; Peng, X. Biodegradable Drug-Loaded Hydroxyapatite Nanotherapeutic Agent for Targeted Drug Release in Tumors. ACS Appl. Mater. Interfaces 2018, 10 (9), 7832-7840.

(16) Verberckmoes, S. C.; De Broe, M. E.; D'Haese, P. C. Dose-Dependent Effects of Strontium on Osteoblast Function and Mineralization. Kidney Int. 2003, 64 (2), 534-543.

(17) D'Haese, P. C.; Schrooten, I.; Goodman, W. G.; Cabrera, W. E.; Lamberts, L. V.; Elseviers, M. M.; Couttenye, M. M.; De Broe, M. E. Increased Bone Strontium Levels in Hemodialysis Patients with Osteomalacia. Kidney Int. 2000, 57 (3), 1107-1114.

(18) Schrooten, I.; Cabrera, W.; Goodman, W. G.; Dauwe, S.; Lamberts, L. V.; Marynissen, R.; Dorriné, W.; De Broe, M. E.; D'Haese, P. C. Strontium Causes Osteomalacia in Chronic Renal Failure Rats. Kidney Int. 1998, 54 (2), 448-456.

(19) Lao, J.; Jallot, E.; Nedelec, J. M. Strontium-Delivering Glasses with Enhanced Bioactivity: A New Biomaterial for Antiosteoporotic Applications? Chem. Mater. 2008, 20 (15), 4969-4973.

(20) Dahl, S. G.; Allain, P.; Marie, P. J.; Mauras, Y.; Boivin, G.; Ammann, P.; Tsouderos, Y.; Delmas, P. D.; Christiansen, C. Incorporation and Distribution of Strontium in Bone. Bone 2001, 28 (4), 446-453.

(21) Schumacher, M.; Gelinsky, M. Strontium Modified Calcium Phosphate CementsApproaches towards Targeted Stimulation of Bone Turnover. J. Mater. Chem. B 2015, $4626,4626$.

(22) Loste, E.; Park, R. J.; Warren, J.; Meldrum, F. C. Precipitation of Calcium Carbonate in Confinement. Adv. Funct. Mater. 2004, 14 (12), 1211-1220.

(23) Kim, Y. Y.; Hetherington, N. B. J.; Noel, E. H.; Kröger, R.; Charnock, J. M.; Christenson, H. K.; Meldrum, F. C. Capillarity Creates Single-Crystal Calcite Nanowires from Amorphous Calcium Carbonate. Angew. Chemie - Int. Ed. 2011, 50 (52), 1257212577.

(24) Kokubo, T.; Takadama, H. How Useful Is SBF in Predicting in Vivo Bone Bioactivity? Biomaterials 2006, 27 (15), 2907-2915.

(25) Mosmann, T. Rapid Colorimetric Assay for Cellular Growth and Survival: Application to Proliferation and Cytotoxicity Assays. J. Immunol. Methods 1983, 65 (1-2), 55-63.

(26) Simão, A. M. S.; Beloti, M. M.; Rosa, A. L.; de Oliveira, P. T.; Granjeiro, J. M.; Pizauro, 
J. M.; Ciancaglini, P. Culture of Osteogenic Cells from Human Alveolar Bone: A Useful Source of Alkaline Phosphatase. Cell Biol. Int. 2007, 31 (11), 1405-1413.

(27) Hartree, E. F. Determination of Protein: A Modification of the Lowry Method That Gives a Linear Photometric Response. Anal. Biochem. 1972, 48 (2), 422-427.

(28) Gregory, C. A.; Gunn, W. G.; Peister, A.; Prockop, D. J. An Alizarin Red-Based Assay of Mineralization by Adherent Cells in Culture: Comparison with Cetylpyridinium Chloride Extraction. Anal. Biochem. 2004, 329 (1), 77-84.

(29) Legeros, R. Z.; Trautz, O. R.; Legeros, J. P.; Klein, E.; Shirra, W. P. Apatite Crystallites: Effects of Carbonate on Morphology. Science (80-. ). 1967, 155 (3768), 1409-1411.

(30) Reznikov, N.; Shahar, R.; Weiner, S. Bone Hierarchical Structure in Three Dimensions. Acta Biomater. 2014, 10 (9), 3815-3826.

(31) Nassif, N.; Martineau, F.; Syzgantseva, O.; Gobeaux, F.; Willinger, M.; Coradin, T.; Cassaignon, S.; Azaïs, T.; Giraud-Guille, M. M. In Vivo Inspired Conditions to Synthesize Biomimetic Hydroxyapatite. Chem. Mater. 2010, 22 (12), 3653-3663.

(32) Tovani, C. B.; Gloter, A.; Azaïs, T.; Selmane, M.; Ramos, A. P.; Nassif, N. Formation of Stable Strontium-Rich Amorphous Calcium Phosphate: Possible Effects on Bone Mineral. Acta Biomater. 2019, 92, 315-324.

(33) Tovani, C. B.; Oliveira, T. M.; Gloter, A.; Ramos, A. P. Sr2+-Substituted CaCO3Nanorods: Impact on the Structure and Bioactivity. Cryst. Growth Des. 2018, 18 (5), 2932-2940.

(34) Boskey, A. L. Mineralization of Bones and Teeth. Elements 2007, 3 (6), 385-391.

(35) Farlay, D.; Boivin, G.; Panczer, G.; Lalande, A.; Meunier, P. J. Long-Term Strontium Ranelate Administration in Monkeys Preserves Characteristics of Bone Mineral Crystals and Degree of Mineralization of Bone. J. Bone Miner. Res. 2005, 20 (9), 1569-1578.

(36) Wang, X.; Yang, J.; Andrei, C. M.; Soleymani, L.; Grand, K. Biomineralization of Calcium Phosphate Revealed by in Situ Liquid-Phase Electron Microscopy. Commun. Chem. 2018, 1 (1), 80.

(37) Shih, Y. R. V.; Hwang, Y.; Phadke, A.; Kang, H.; Hwang, N. S.; Caro, E. J.; Nguyen, S.; Siu, M.; Theodorakis, E. A.; Gianneschi, N. C.; Vecchio,K. S.; Chien, S.; Lee, O. K.; Varghese, S. Calcium Phosphate-Bearing Matrices Induce Osteogenic Differentiation of Stem Cells through Adenosine Signaling. Proc. Natl. Acad. Sci. U. S. A. 2014, 111 (3), 990-995.

(38) Wang, Y. W.; Christenson, H. K.; Meldrum, F. C. Confinement Increases the Lifetimes of Hydroxyapatite Precursors. Chem. Mater. 2014, 26 (20), 5830-5838.

(39) Meldrum, F. C.; O'Shaughnessy, C. Crystallization in Confinement. Adv. Mater. 2020, $32(31), 2001068$.

(40) Ihli, J.; Wang, Y.-W.; Cantaert, B.; Kim, Y.-Y.; Green, D. C.; Bomans, P. H. H.; Sommerdijk, N. A. J. M.; Meldrum, F. C. Precipitation of Amorphous Calcium Oxalate in Aqueous Solution. Chem. Mater. 2015, 27 (11), 3999-4007.

(41) Anduix-Canto, C.; Kim, Y. Y.; Wang, Y. W.; Kulak, A.; Meldrum, F. C.; Christenson, H. K. Effect of Nanoscale Confinement on the Crystallization of Potassium Ferrocyanide. Cryst. Growth Des. 2016, 16 (9), 5403-5411.

(42) Lotsari, A.; Rajasekharan, A. K.; Halvarsson, M.; Andersson, M. Transformation of Amorphous Calcium Phosphate to Bone-like Apatite. Nat. Commun. 2018, 9 (1), 4170.

(43) Akiva, A.; Kerschnitzki, M.; Pinkas, I.; Wagermaier, W.; Yaniv, K.; Fratzl, P.; Addadi, L.; Weiner, S. Mineral Formation in the Larval Zebra Fi Sh Tail Bone Occurs via an Acidic Disordered Calcium Phosphate Phase. J. Am. Chem. Soc. 2016, 138 (43), 1448114487.

(44) Li, C.; Paris, O.; Siegel, S.; Roschger, P.; Paschalis, E. P.; Klaushofer, K.; Fratzl, P. Strontium Is Incorporated into Mineral Crystals Only in Newly Formed Bone during Strontium Ranelate Treatment. J. Bone Miner. Res. 2010, 25 (5), 968-975.

(45) Chamberlain, T.; Handbook, S. E. Infrared Analysis of Rat Bone : Age Dependency Of. Science. 1966, 153 (3743), 1523-1525.

(46) Cantaert, B.; Beniash, E.; Meldrum, F. C. The Role of Poly(Aspartic Acid) in the Precipitation of Calcium Phosphate in Confinement. J. Mater. Chem. B 2013, 1 (48), 
6586-6595.

(47) Procopio, A.; Malucelli, E.; Pacureanu, A.; Cappadone, C.; Farruggia, G.; Sargenti, A.; Castiglioni, S.; Altamura, D.; Sorrentino, A.; Giannini, C.; Pereiro, E.; Cloetens, P.; Maier, J. A. M., Iotti, S. Chemical Fingerprint of Zn-Hydroxyapatite in the Early Stages of Osteogenic Differentiation. ACS Cent. Sci. 2019, 5 (8), 1449-1460.

(48) Frankær, C. G.; Raffalt, A. C.; Stahl, K. Strontium Localization in Bone Tissue Studied by X-Ray Absorption Spectroscopy. Calcif. Tissue Int. 2014, 94 (2), 248-257.

(49) Cruz, M. A. E.; Zanatta, M. B. T.; da Veiga, M. A. M. S.; Ciancaglini, P.; Ramos, A. P. Lipid-Mediated Growth of $\mathrm{SrCO} 3 / \mathrm{CaCO} 3$ Hybrid Films as Bioactive Coatings for Ti Surfaces. Mater. Sci. Eng. C 2019, 99 (February), 762-769.

(50) Kim, H. M.; Himeno, T.; Kokubo, T.; Nakamura, T. Process and Kinetics of Bonelike Apatite Formation on Sintered Hydroxyapatite in a Simulated Body Fluid. Biomaterials 2005, 26 (21), 4366-4373.

(51) Leite, Á. J.; Gonçalves, A. I.; Rodrigues, M. T.; Gomes, M. E.; Mano, J. F. StrontiumDoped Bioactive Glass Nanoparticles in Osteogenic Commitment. ACS Appl. Mater. Interfaces 2018, 10 (27), 23311-23320.

(52) Jilka, R. L. Biology of the Basic Multicellular Unit and the Pathophysiology of Osteoporosis. Med. Pediatr. Oncol. 2003, 41 (3), 182-185.

(53) Uggeri, J.; Guizzardi, S.; Scandroglio, R.; Gatti, R. Adhesion of Human Osteoblasts to Titanium: A Morpho-Functional Analysis with Confocal Microscopy. Micron 2010, 41 (3), 210-219.

(54) Suphasiriroj, W.; Yotnuengnit, P.; Surarit, R.; Pichyangkura, R. The Fundamental Parameters of Chitosan in Polymer Scaffolds Affecting Osteoblasts (MC3T3-E1). $J$. Mater. Sci. Mater. Med. 2009, 20 (1), 309-320.

(55) Bonnelye, E.; Chabadel, A.; Saltel, F.; Jurdic, P. Dual Effect of Strontium Ranelate: Stimulation of Osteoblast Differentiation and Inhibition of Osteoclast Formation and Resorption in Vitro. Bone 2008, 42 (1), 129-138.

(56) Meunier, P. J.; Roux, C.; Seeman, E.; Ortolani, S.; Badurski, J. E.; Spector, T. D.; Cannata, J.; Balogh, A.; Lemmel, E. M.; Pors-Nielsen, S.; Rizzoli, R.; Genant, H. K.; Reginster, J.Y. The Effects of Strontium Ranelate on the Risk of Vertebral Fracture in Women with Postmenopausal Osteoporosis. N. Engl. J. Med. 2004, 350 (5), 459-468.

(57) Oste, L.; Bervoets, A. R.; Behets, G. J.; Dams, G.; Marijnissen, R. L.; Geryl, H.; Lamberts, L. V.; Verberckmoes, S. C.; Van Hoof, V. O.; De Broe, M. E.; D'Haese, P. C. Time-Evolution and Reversibility of Strontium-Induced Osteomalacia in Chronic Renal Failure Rats. Kidney Int. 2005, 67 (3), 920-930.

(58) Sifert, R. S. The Role of Alkaline Phosphatase in Osteogenesis. J. Exp. Med. 1951, 93 (5), 415-426.

(59) Cruz, M. A. E.; Tovani, C. B.; Favarin, B. Z.; Soares, M. P. R.; Fukada, S. Y.; Ciancaglini, P.; Ramos, A. P. Synthesis of Sr-Morin Complex and Its: In Vitro Response: Decrease in Osteoclast Differentiation While Sustaining Osteoblast Mineralization Ability. J. Mater. Chem. B 2019, 7 (5), 823-829.

(60) Xie, H.; Gu, Z.; He, Y.; Xu, J.; Xu, C.; Li, L.; Ye, Q. Microenvironment Construction of Strontium-Calcium-Based Biomaterials for Bone Tissue Regeneration: The Equilibrium Effect of Calcium to Strontium. J. Mater. Chem. B 2018, 6 (15), 2332-2339.

(61) Li, K.; Dai, F.; Yan, T.; Xue, Y.; Zhang, L.; Han, Y. Magnetic Silicium Hydroxyapatite Nanorods for Enhancing Osteoblast Response in Vitro and Biointegration in Vivo. ACS Biomater. Sci. Eng. 2019, 5, 2208-2221.

(62) Basu, S.; Ghosh, A.; Barui, A.; Basu, B. (Fe/Sr) Codoped Biphasic Calcium Phosphate with Tailored Osteoblast Cell Functionality. ACS Biomater. Sci. Eng. 2018, 4 (3), 857871.

(63) Weng, L.; Boda, S. K.; Teusink, M. J.; Shuler, F. D.; Li, X.; Xie, J. Binary Doping of Strontium and Copper Enhancing Osteogenesis and Angiogenesis of Bioactive Glass Nanofibers While Suppressing Osteoclast Activity. ACS Appl. Mater. Interfaces 2017, 9 (29), 24484-24496.

(64) Boda, S. K.; Thrivikraman, G.; Panigrahy, B.; Sarma, D. D.; Basu, B. Competing Roles 
of Substrate Composition, Microstructure, and Sustained Strontium Release in Directing Osteogenic Differentiation of HMSCs. ACS Appl. Mater. Interfaces 2017, 9 (23), 19389-19408.

(65) Deng, Y.; Liu, M.; Chen, X.; Wang, M.; Li, X.; Xiao, Y.; Zhang, X. Enhanced Osteoinductivity of Porous Biphasic Calcium Phosphate Ceramic Beads with High Content of Strontium-Incorporated Calcium-Deficient Hydroxyapatite. J. Mater. Chem. $B$ 2018, 6 (41), 6572-6584.

(66) Cai, X.; Han, B.; Liu, Y.; Tian, F.; Liang, F.; Wang, X. Chlorhexidine-Loaded Amorphous Calcium Phosphate Nanoparticles for Inhibiting Degradation and Inducing Mineralization of Type i Collagen. ACS Appl. Mater. Interfaces 2017, 9 (15), 1294912958.

(67) Yu, W.; Sun, T. W.; Qi, C.; Ding, Z.; Zhao, H.; Chen, F.; Chen, D.; Zhu, Y. J.; Shi, Z.; He, Y. Strontium-Doped Amorphous Calcium Phosphate Porous Microspheres Synthesized through a Microwave-Hydrothermal Method Using Fructose 1,6Bisphosphate as an Organic Phosphorus Source: Application in Drug Delivery and Enhanced Bone Regeneration. ACS Appl. Mater. Interfaces 2017, 9 (4), 3306-3317.

(68) Ribeiro, A. R.; Gemini-Piperni, S.; Travassos, R.; Lemgruber, L.; Silva, R. C.; Rossi, A. L.; Farina, M.; Anselme, K.; Shokuhfar, T.; Shahbazian-Yassar, R.; Borojevic, R.; Rocha, L.A.; Werckmann, J.; Granjeiro J.M. Trojan-Like Internalization of Anatase Titanium Dioxide Nanoparticles by Human Osteoblast Cells. Sci. Rep. 2016, 6 (3), 1-11.

(69) Capuccini, C.; Torricelli, P.; Sima, F.; Boanini, E.; Ristoscu, C.; Bracci, B.; Socol, G.; Fini, M.; Mihailescu, I. N.; Bigi, A. Strontium-Substituted Hydroxyapatite Coatings Synthesized by Pulsed-Laser Deposition: In Vitro Osteoblast and Osteoclast Response. Acta Biomater. 2008, 4 (6), 1885-1893.

(70) Gentleman, E.; Fredholm, Y. C.; Jell, G.; Lotfibakhshaiesh, N.; O’Donnell, M. D.; Hill, R. G.; Stevens, M. M. The Effects of Strontium-Substituted Bioactive Glasses on Osteoblasts and Osteoclasts in Vitro. Biomaterials 2010, 31 (14), 3949-3956. 
Strontium calcium

phosphate nanotubes
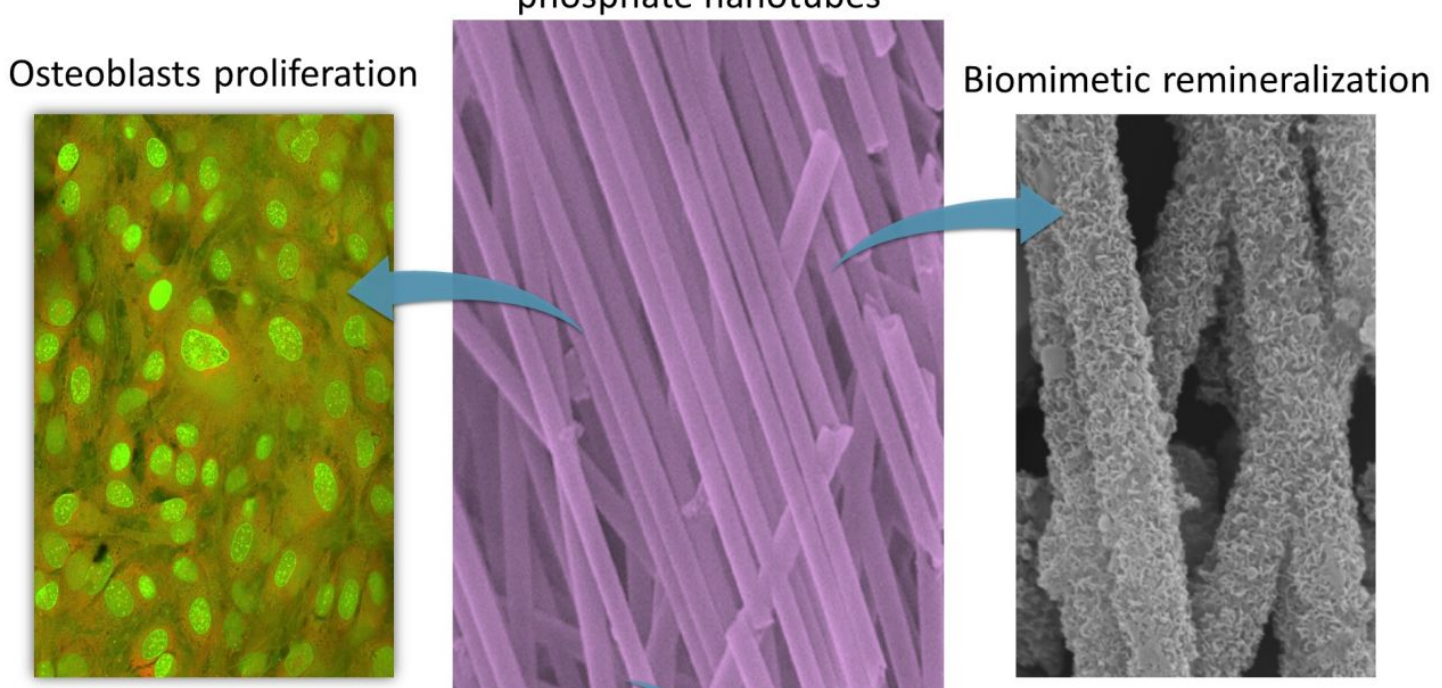

Apatite resorption by osteoclasts
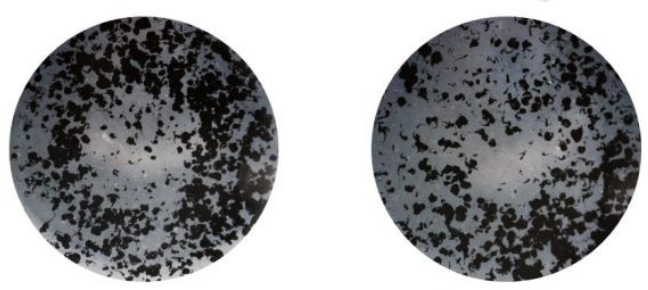

$\mathrm{Sr}^{2+}$ concentration

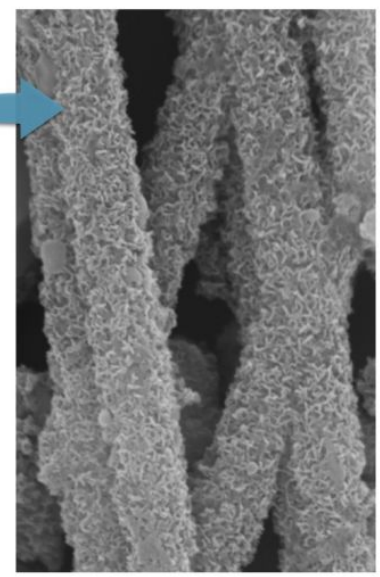

$1 \mu \mathrm{m}$
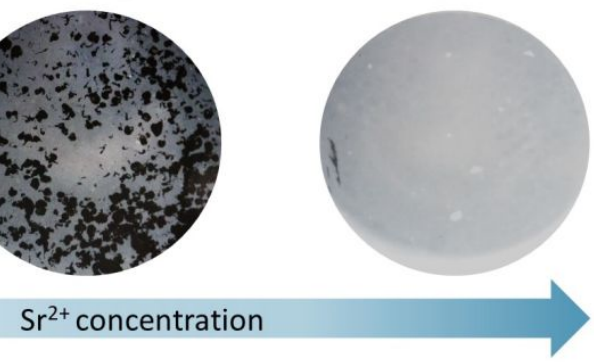


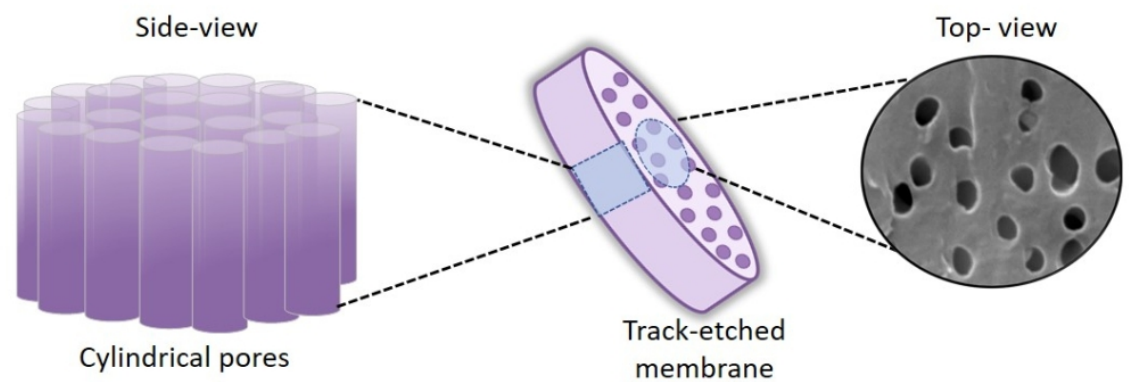

b

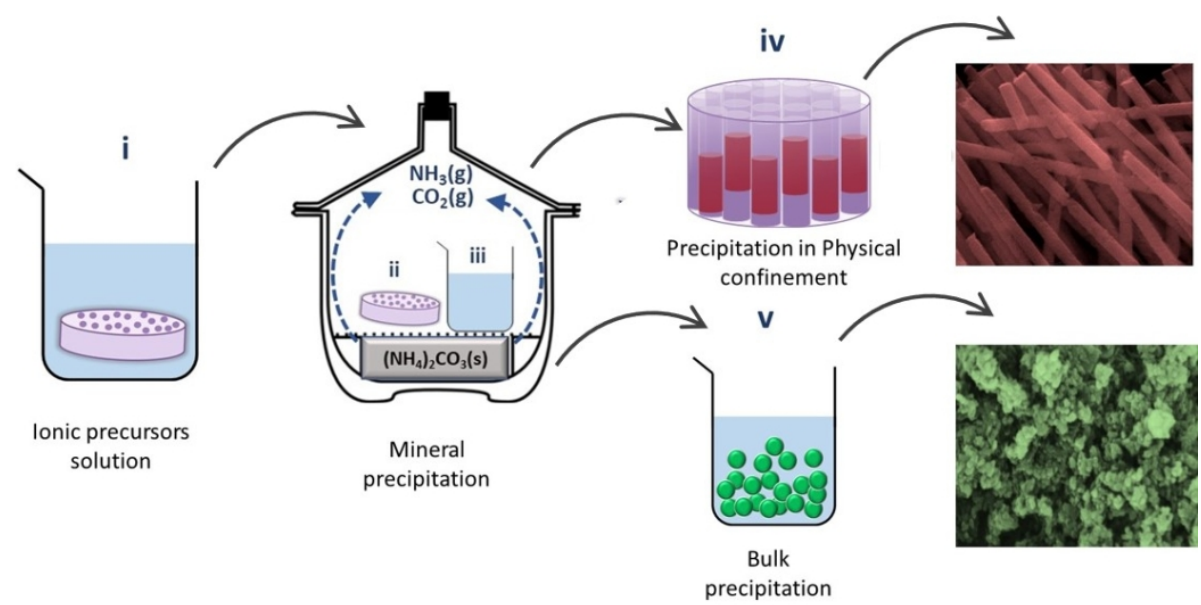

Figure 1. (a) Schematic representation of a track-etched membrane used as physical confinement to tune the morphology and size of the nanotubes. The side and top view of the membrane shows the cylindrical pores where the precipitation takes place. A SEM image of the surface of a membrane shows the pores. (b) Schematic representation of the precipitation of $\mathrm{Sr}(\mathrm{CaP})$ under either physical confinement (i, ii, iv) or in bulk solution (iii and v). The membranes were immersed into the PAA/salt solution for $12 \mathrm{~h}$ ( $\mathrm{i}$ ) and then placed in a desiccator containing ( $\mathrm{NH} 4) 2 \mathrm{CO} 3$ (ii) leading to the formation of nanotubes inside the cylindrical pores (iv). The particles (reddish SEM image) were isolated by dissolving the membranes with chloroform followed by centrifugation. A beaker containing the PAA/salt solutions was placed in the desiccator (iii) to conduct the precipitation from bulk solution ( $v$ ) leading to agglomerated spherical particles (greenish SEM image). 
Figure 2. SEM images of the phosphate particles formed in bulk solution (a) and in confinement (b). XRD pattern of the particles synthesized in bulk solution (c) and in confinement (d). The products formed in bulk solution were indexed as follows: hydroxyapatite for 0\% Sr2+ and 10\% Sr 2+ (JCPDS 9-432). The additional peaks $\left(^{*}\right)$ observed in the $0 \% \mathrm{Sr}+$ sample may be due to OCP (JPDCS 26-1056). Strontianite (S) (JPDCS 01-071-4899) was found in the 50\% Sr2+ sample in addition to an amorphous phase Sr(ACP). Strontium hydrogen phosphate was identified in the 100\% Sr2+ sample (JCPDS 23-105026). The samples formed in confinement were identified as hydroxyapatite (0\% Sr2+), $\mathrm{Sr}(\mathrm{ACP})(10 \% \mathrm{Sr} 2+$ and $50 \% \mathrm{Sr} 2+$ ) and strontium hydroxyapatite ( $100 \%$ Sr2+) (JPDCS 33-1348).

$1064 \times 875 \mathrm{~mm}(120 \times 120 \mathrm{DPI})$ 


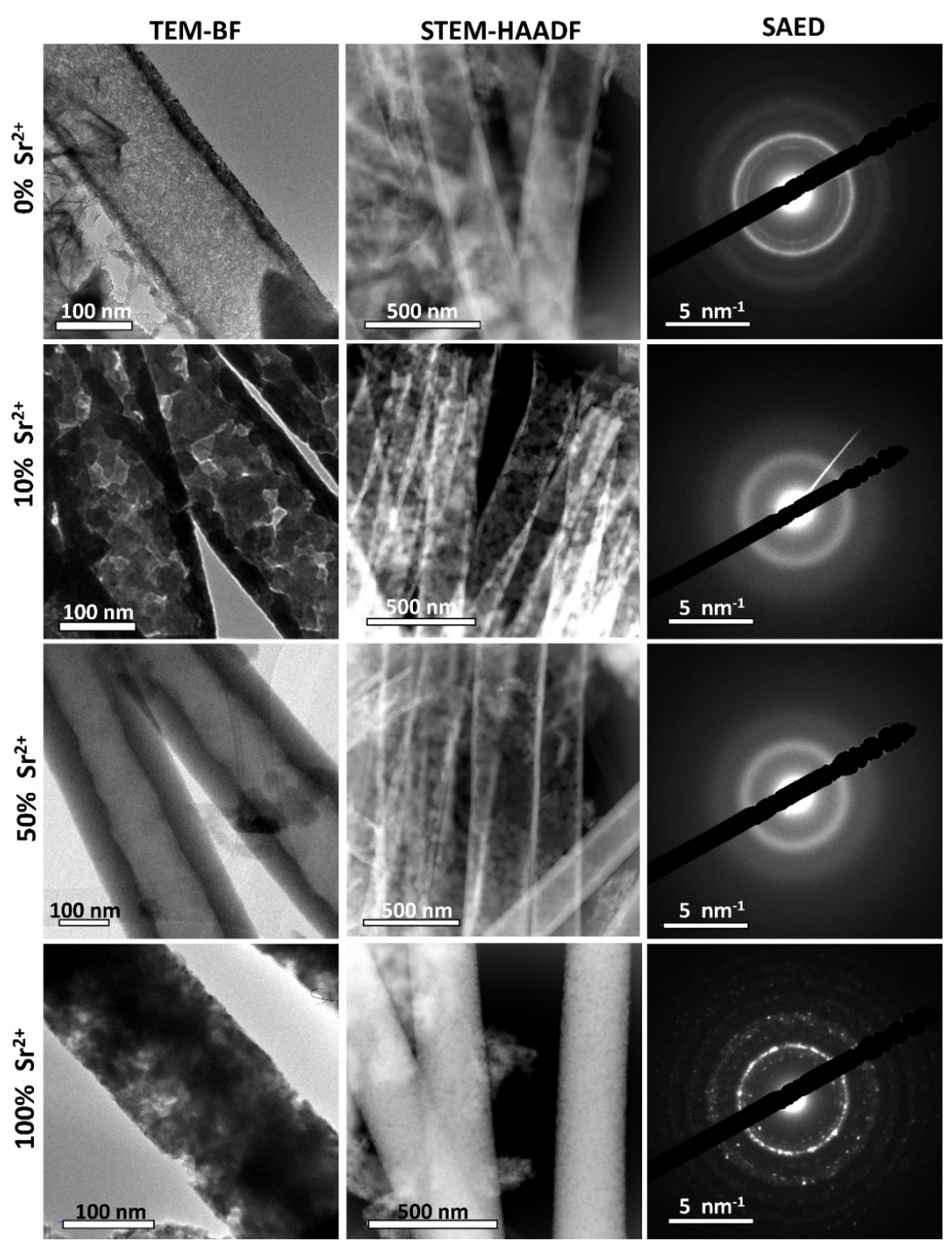

Figure 3.TEM-BF, STEM-HAADF images and SAED patterns of the tubes 0, 10, 50, and 100\% Sr2+. STEMHAADF images show that the 0\% Sr2+, 10\% Sr2+ and 50\% Sr2+ tubes are hollow. The absence of crystalline reflections in the SAED patterns of the $10 \% \mathrm{Sr} 2+$ and $50 \% \mathrm{Sr}+$ tubes confirms their amorphous character depicted by XRD.

$134 \times 176 \mathrm{~mm}(220 \times 220 \mathrm{DPI})$ 

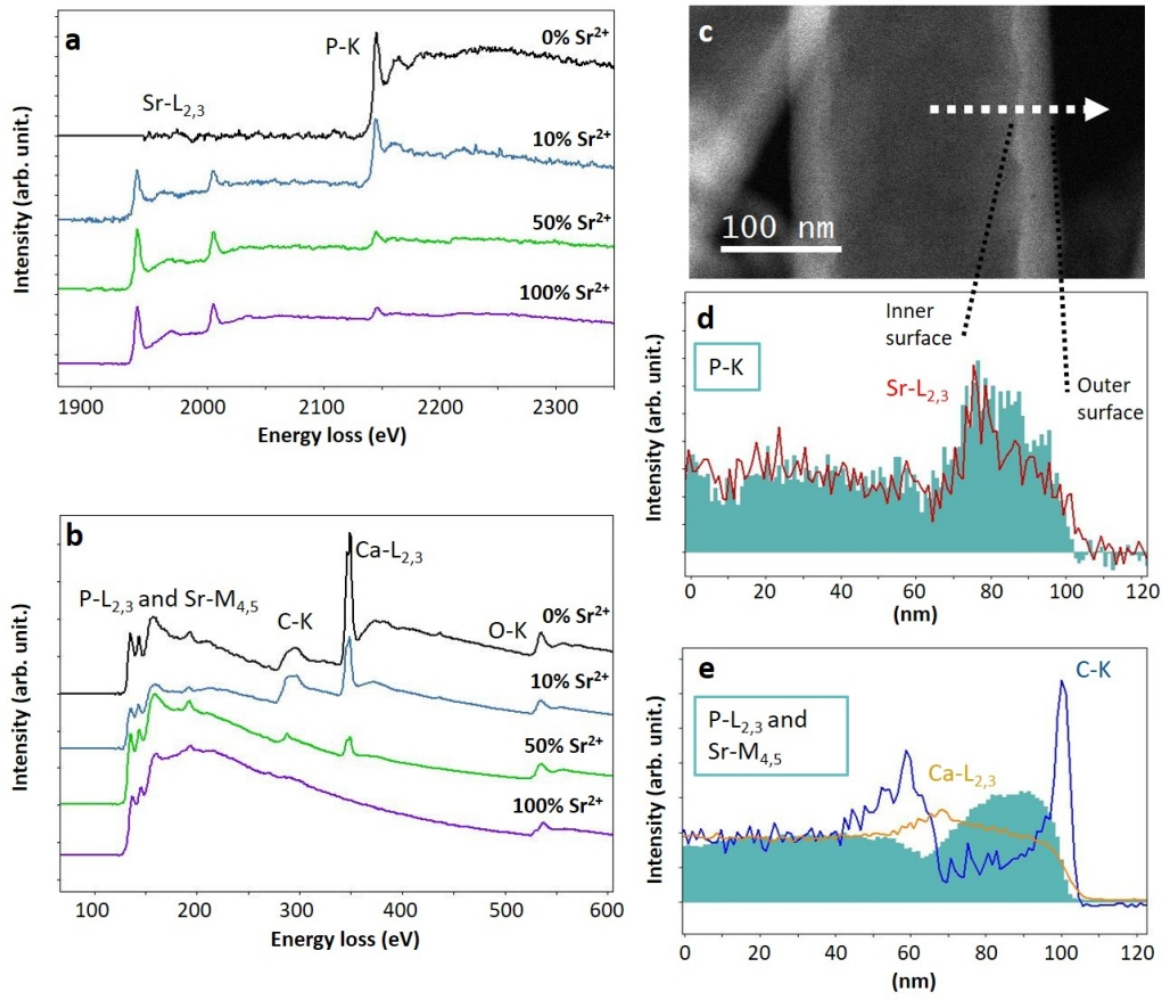

Figure 4. (a,b) EELS spectra of the tubes containing $0 \% \mathrm{Sr} 2+, 10 \% \mathrm{Sr} 2+, 50 \% \mathrm{Sr} 2+$ and $100 \% \mathrm{Sr} 2+$. (c,d,e) EELS spectromicroscopy performed on the $50 \% \mathrm{Sr} 2+$ tube showing the presence of several compositional heterogeneities.

$242 \times 188 \mathrm{~mm}(150 \times 150 \mathrm{DPI})$ 

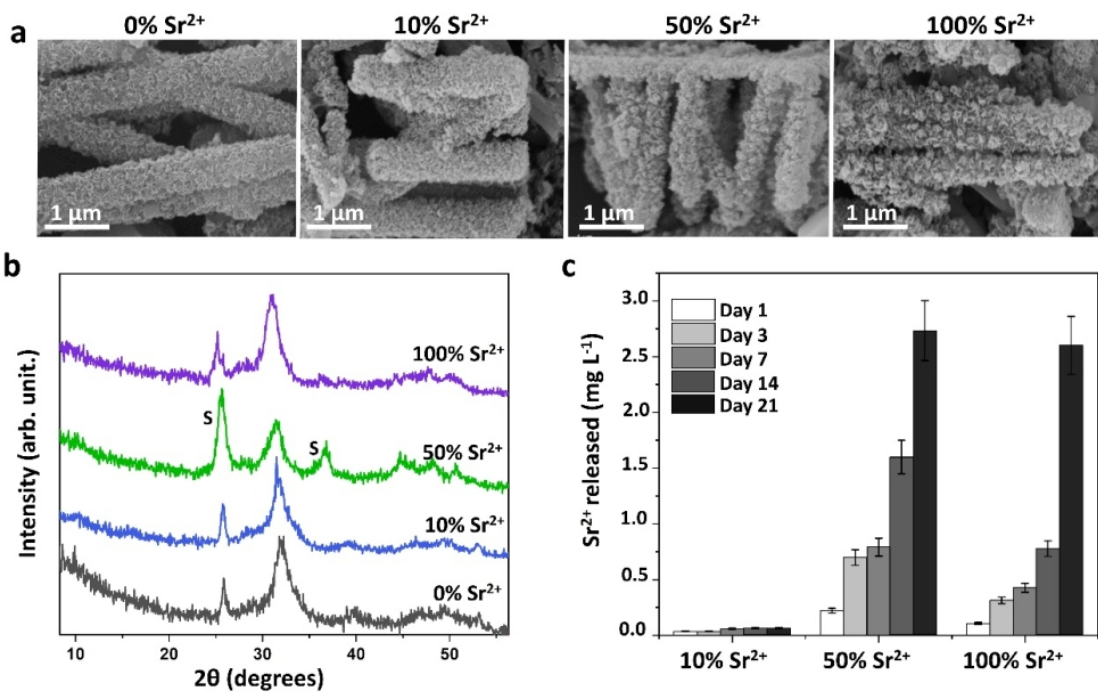

c

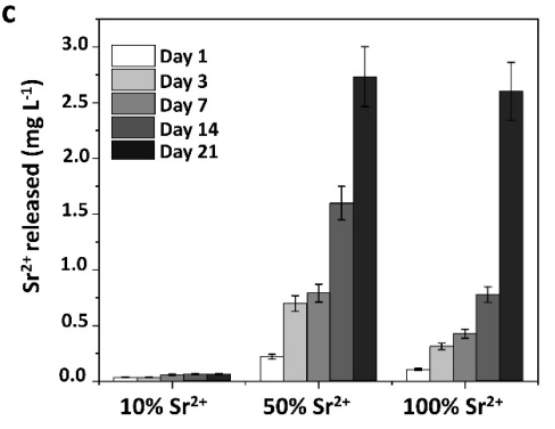

Figure 5. (a) SEM images and (b) X-ray diffraction patterns of the tubes containing different amounts of $\mathrm{Sr} 2+$ after 5 days of immersion into SBF. The diffractograms were indexed with the hydroxyapatite structure (JCPDS 9-432). The 50\% Sr2+ sample led to the additional formation of SrCO3 as observed by the additional peaks at $2 \theta=25^{\circ}$ and $35^{\circ}$ (indicated by $S$ in the diffractogram). (c) Sr2+released from the $10 \%$ $\mathrm{Sr} 2+, 50 \% \mathrm{Sr} 2+$ and $100 \% \mathrm{Sr} 2+$ tubes immersed in the cell culture medium at $37{ }^{\circ} \mathrm{C}$ for 12 hours, 1, 3, 7 , 14 and 21 days. The amount of Sr2+ released by the particles falls in the therapeutic doses used for osteoporosis treatment.

$169 \times 96 \mathrm{~mm}(220 \times 220$ DPI $)$ 


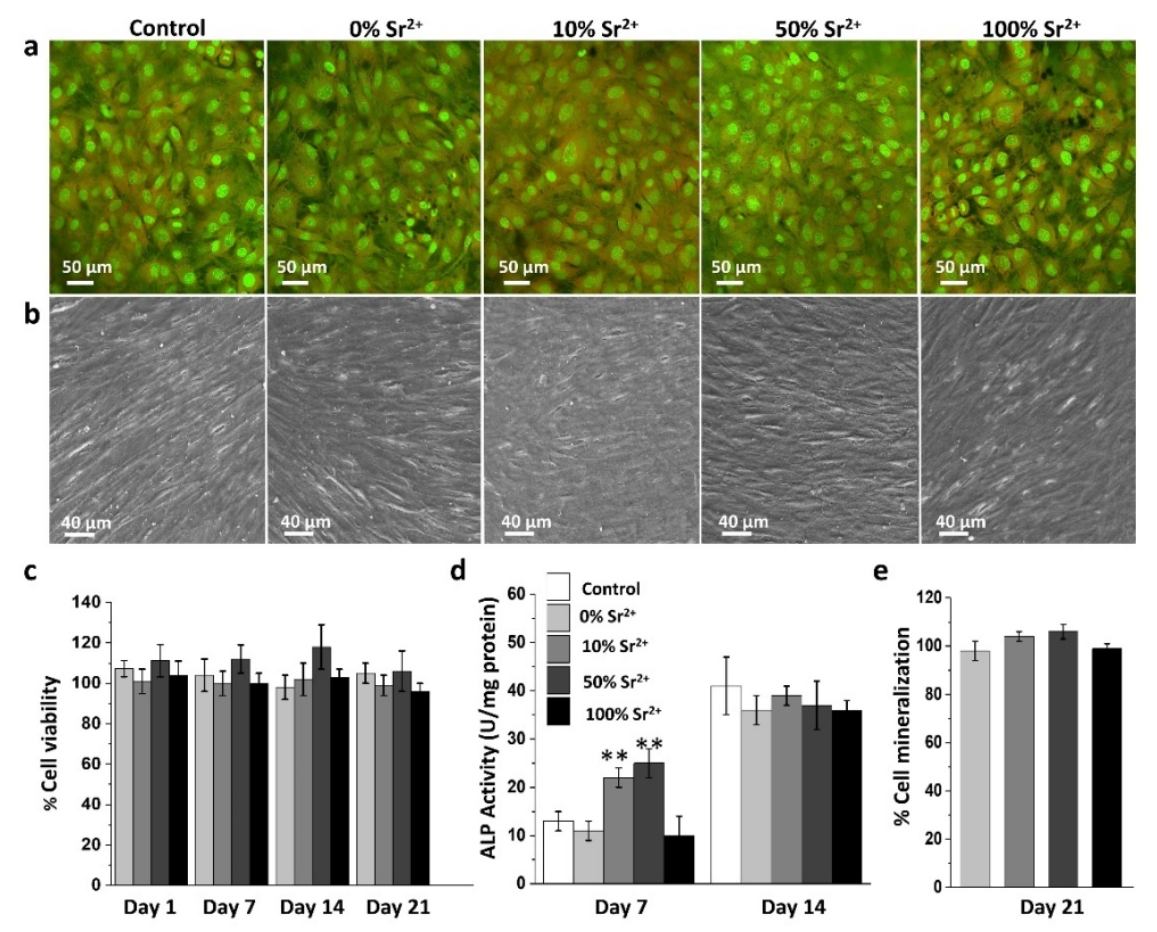

Figure 6. (a) Confocal microscopy and (b) SEM images of MC3T3-E1 cells cultured for 7 and 21 days respectively, in the absence (control) and in the presence of $\mathrm{Sr}(\mathrm{CaP})$ tubes containing $0 \% \mathrm{Sr} 2+, 10 \% \mathrm{Sr} 2+$, $50 \% \mathrm{Sr} 2+$ and $100 \% \mathrm{Sr} 2+$. (c) Cell viability versus control measured by MTT assay after $24 \mathrm{~h}, 7,14$ and 21 days of culture, (d) activity of ALP in the osteoblasts' membrane fraction after 7 and14 days of culture and (e) quantification of mineralized nodules formed in the wells after 21 days of culture. Results represent the mean values \pm standard deviation for triplicate determination for each experiment. Multiple statistical comparisons were performed by two-way ANOVA, $* * p<0.01$.

$149 \times 112 \mathrm{~mm}(220 \times 220$ DPI $)$ 

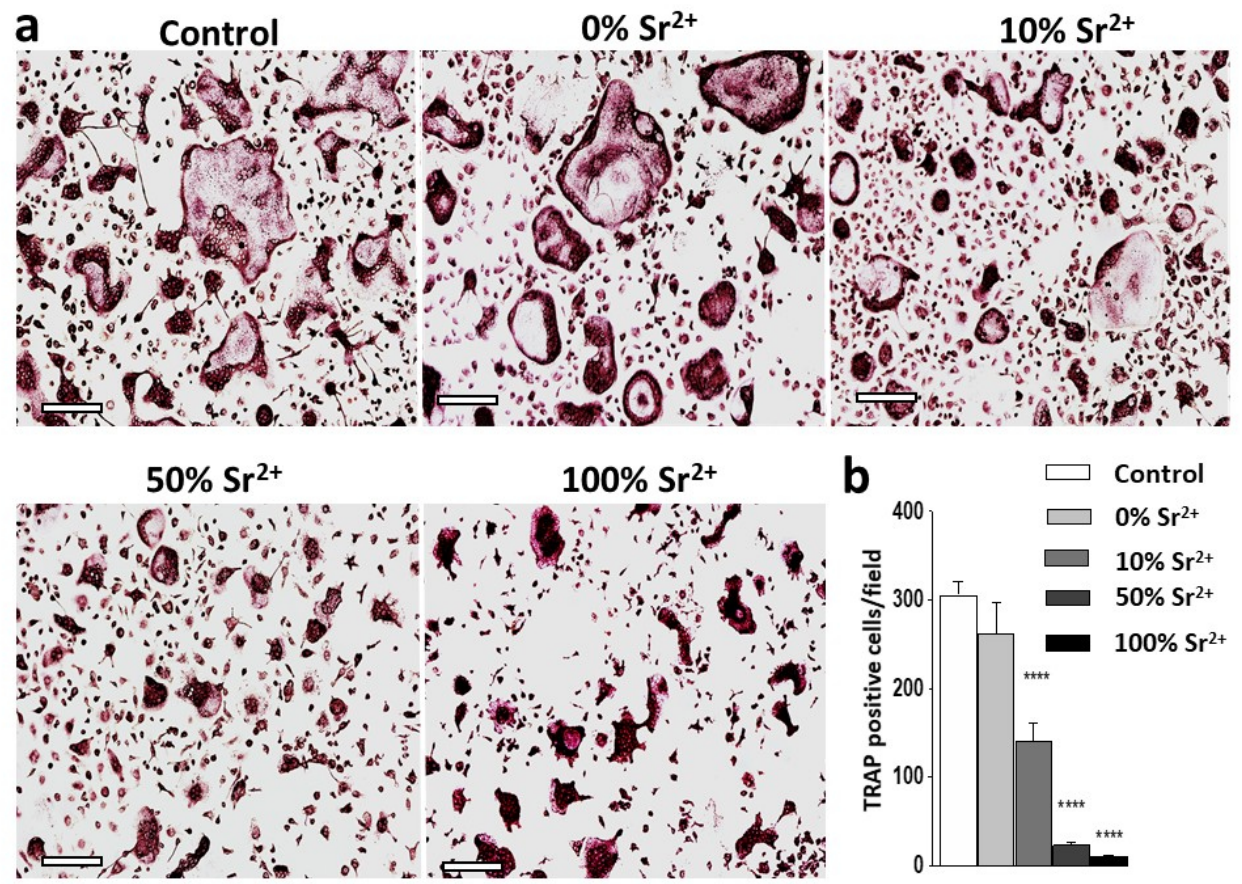

b

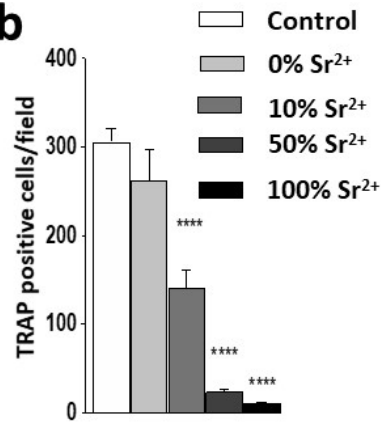

Figure 7. (a) Representative images and (b) quantification of TRAP-positive osteoclasts cultured for 4 days. Bone marrow macrophages (BMMs) was cultured under M-CSF and RANKL stimulation, in the absence (control) and in the presence of the Sr(CaP) tubes containing 0\% Sr2+, 10\% Sr2+, 50\% Sr2+ and 100\% $\mathrm{Sr} 2+$. Results represent the mean value \pm standard deviation $(n=5)$ representative of two independent experiments. One-way ANOVA, followed by Tukey's post-test. $* * * * p<0.001$, compared to control. Scales bars represent $100 \mu \mathrm{m}$

$210 \times 152 \mathrm{~mm}(120 \times 120 \mathrm{DPI})$ 
a

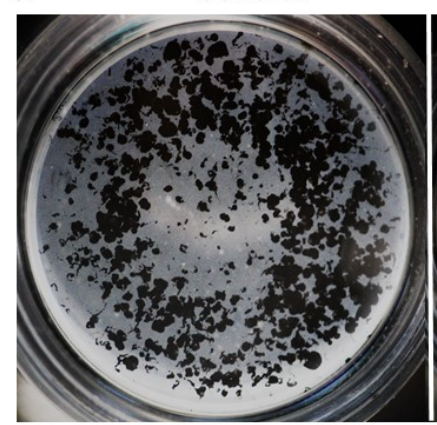

$0 \% \mathrm{Sr}^{2+}$
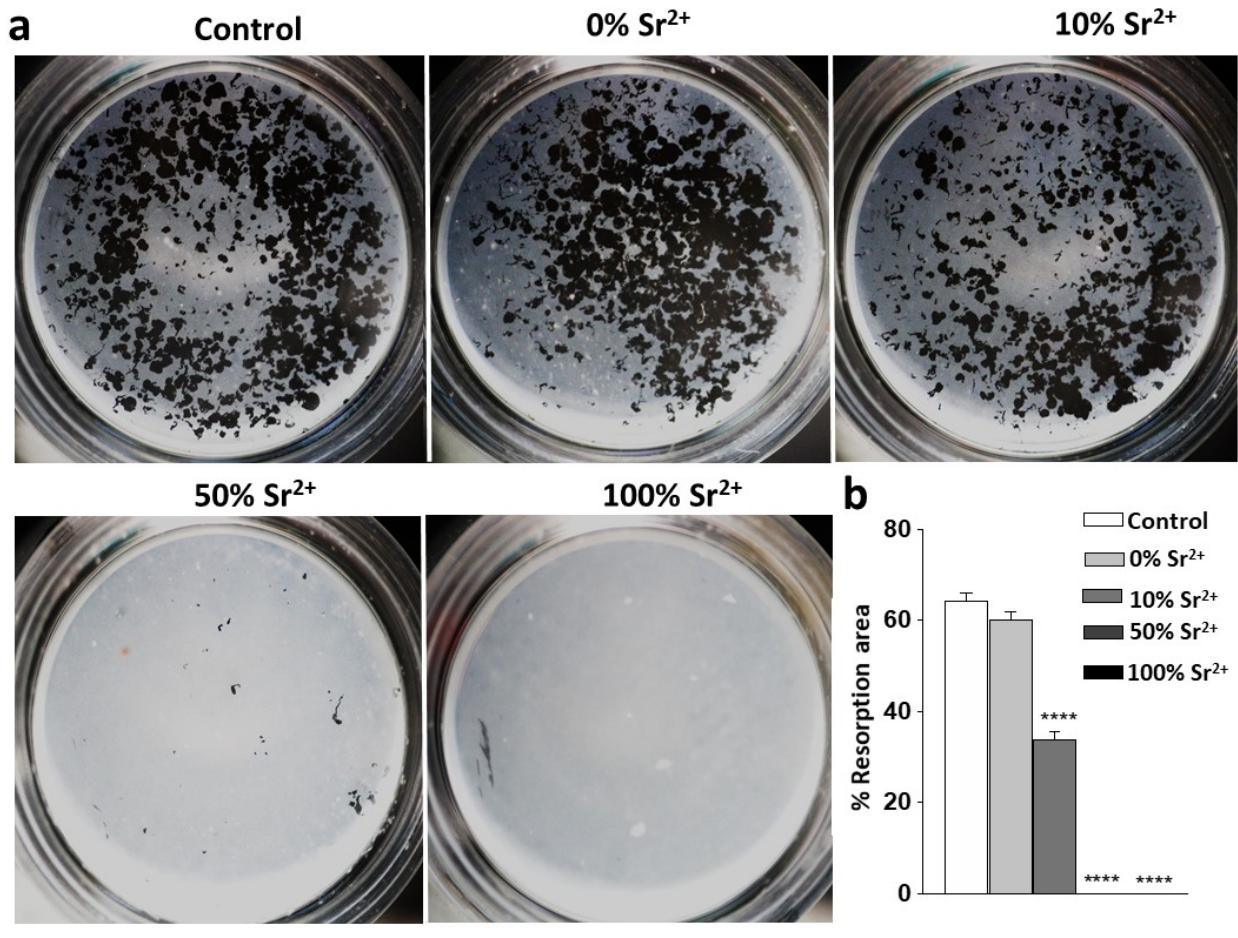

b
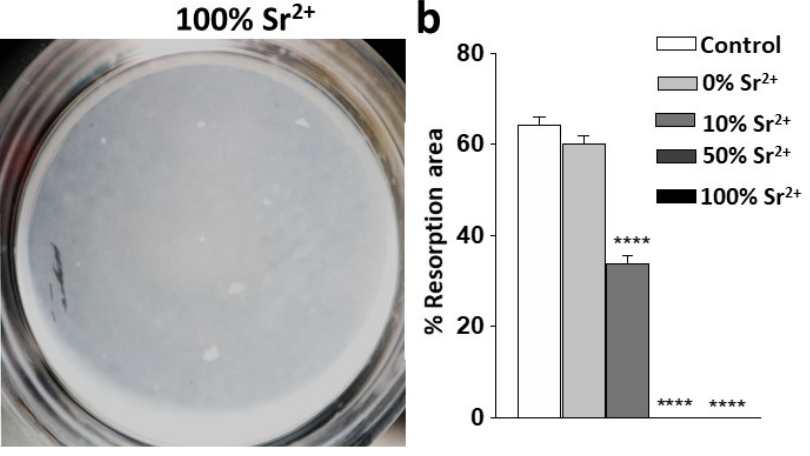

Figure 8. (a) Representative images and (b) quantification of resorption area induced by osteoclasts cultured in hydroxyapatite-coated plates for 5 days. Bone marrow macrophages (BMMs) was cultured under M-CSF and RANKL in hydroxyapatite-coated plates, in the absence (control) and in the presence of $\mathrm{Sr}(\mathrm{CaP})$ tubes containing $0 \% \mathrm{Sr} 2+, 10 \% \mathrm{Sr} 2+, 50 \% \mathrm{Sr} 2+$ and $100 \% \mathrm{Sr} 2+$. Results represent the mean value \pm standard deviation $(n=5)$ representative of two independent experiments. One-way ANOVA, followed by Tukey's posttest. $* * * * p<0.001$, compared to control.

$234 \times 170 \mathrm{~mm}(120 \times 120 \mathrm{DPI})$ 


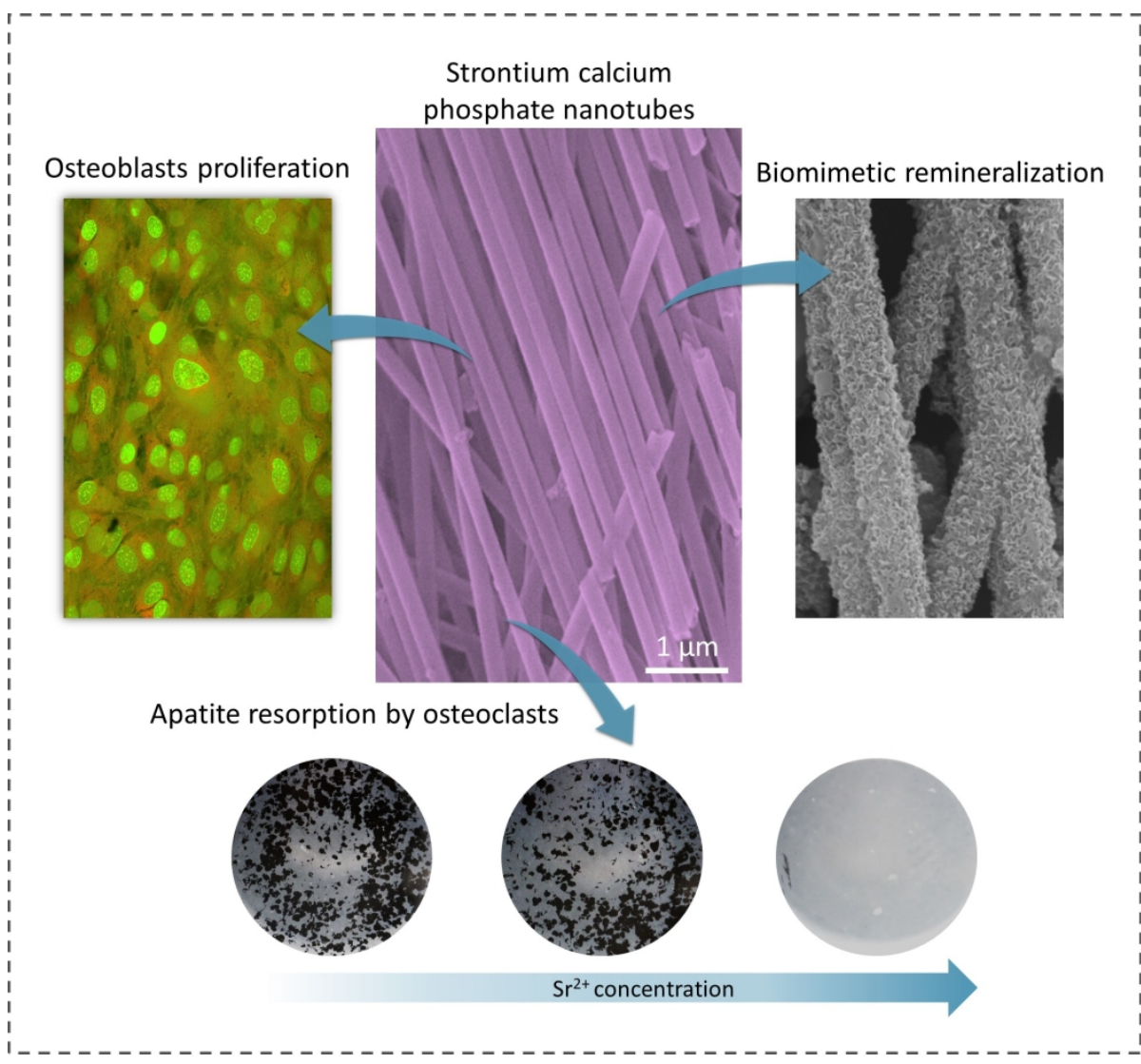

$454 \times 382 \mathrm{~mm}(120 \times 120 \mathrm{DPI})$ 